\title{
The Role of Hepatic Stellate Cells and Angiogenesis in Liver Regeneration Following Partial Hepatectomy in Adult Male Albino Rats: Histological and Immunohistochemical Study
}

Original

Soad Jimmy ${ }^{1}$, Dalia Elmarakby ${ }^{1}$,Maha Abo Gazia', Ahmed Morsy ${ }^{3}$

Department of Histology, Faculty of Medicine, ${ }^{I}$ Cairo University ${ }^{2}$ Khafrelskeikh University, ${ }^{3}$ Fayoum University, Egypt

\begin{abstract}
Introduction: Partial hepatectomy is indicated as the main curative approach for traumatic rupture of the hepatic parenchyma, and hepatocellular carcinoma. Hepatic stellate cells (HSCs) are vital and have a significant importance in their emerging role in hepatic regeneration.

Aim of the Work: Study the role of hepatic stellate cells and angiogenesis in liver regeneration after 70\% partial hepatectomy in adult male albino rats.

Materials and Methods: Forty adult male albino rats(4-6months) weighing 150-200 gm were randomized into 5 groups of eight rats each; group I was the sham control group, and the animals were subjected to $70 \%$ partial hepatectomy in groups II, III, IV and V in which they were postoperatively sacrificed 3, 7, 14 and 21 days respectively. At the time of scarification specimens were taken for histological and immunohistochemical studies. $\mathrm{H}$ and $\mathrm{E}$ and immunohistochemical staining for proliferating cell nuclear antigen (PCNA), vascular endothelial growth factor (VEGF) and $\alpha$-smooth muscle actin $(\alpha$ - SMA) were done. Image analysis and statistical analysis of the obtained results were performed.

Results: The liver showed disturbed histological architecture with distortion of the neatly arranged hepatocyte plates in group II which was restored in the following groups. Wide distribution of Kupffer cells, was also noted in group II and continued in group III. The PCNA and VEGF activity showed significant positive reaction in groups II and III, insignificant positive immunoreaction was reported in groups IV and V . The $\alpha$ - SMA showed significant positive reaction in group II, insignificant immunoreaction was reported in the remaining other groups.

Conclusion: Partial hepatectomy stimulated liver regeneration in the remaining liver lobes with reconstitution of most of the liver mass 21 days postoperatively. This regenerative process was associated with angiogenesis and HSCs activation as denoted by VEGF expression and $\alpha$ - SMA expression respectively.
\end{abstract}

Received: 16 February 2019, Accepted: 19 February 2019

Key Words: Hepatocellular carcinoma, immunohistochemistry, liver regeneration, partial hepatectomy.

Corresponding Author: Maha Abo Gazia, PhD, Department of Histology, Faculty of Medicine, Khafrelskeikh University, Khafrelskeikh, Egypt, Tel.: +20 1228663099, E-mail: mahaabogazia@yahoo.com

ISSN: $1110-0559$, Vol. 42, No. 4

\section{INTRODUCTION}

Partial hepatectomy $(\mathrm{PH})$ is mainly indicated for primary or secondary tumors of the liver and biliary ducts. It is also indicated for benign lesions such as traumatic rupture of the hepatic parenchyma, hepatic abscesses, polycystic liver disease and liver hydatid cyst ${ }^{[1]}$.

Hepatocellular carcinoma (HCC)is one of the most common liver tumors in Asia and $\mathrm{Africa}^{[2]}$. Partial hepatectomy $(\mathrm{PH})$ and liver transplantation are the preferred treatment modalities as they give a chance of a cure for $\mathrm{HCC}^{[3]}$.

The efficient regeneration of the liver after $\mathrm{PH}$ determines the clinical prognosis of the patient with hepatic malignancies. The wide safety margin resection does not leave enough functioning liver parenchyma after operation $^{[4]}$.
Moreover, in liver transplantation, the characteristic regenerative capacity of the liver is important for the donor to maintain the appropriate mass and function as well as for the recipient to guarantee a good outcome ${ }^{[5]}$.

Liver regeneration is a complicated process. It can be triggered by primary reduction of liver mass as in partial hepatectomy $(\mathrm{PH})$ or liver transplantation with small size grafts. Also, it can be triggered by secondary reduction of a viable liver mass induced by liver injury as in viral hepatitis, drug injury or steatosis ${ }^{[6 a n d 7]}$.

Partial hepatectomy is the most often used model of liver regeneration because it is not associated with tissue injury or inflammation when compared with other methods that use hepatic toxins such as carbon tetrachloride ${ }^{[8 a n d 9]}$.

Liver regeneration can be evaluated by using proliferating cell nuclear antigen (PCNA), an endogenous 
nuclear protein, as a marker of hepatocyte proliferation after $\mathrm{PH}$ in rats ${ }^{[10]}$.

The response of liver regeneration is also thought to be dependent on angiogenesis because the expansion of avascular hepatocyte clusters, formed during regeneration throughout liver lobule, is followed by subsequent proliferation and invasion of the sinusoidal endothelium. This process is stimulated by the release of different angiogenic growth factors including vascular endothelial growth factor (VEGF) which is synthesized by hepatocyte ${ }^{[11]}$. However, the overall requirement of angiogenesis for liver regeneration was even denied by some authors ${ }^{[12]}$.

Hepatic stellate cells (HSCs) have a significant importance in their emerging role in hepatic fibrosis. There is growing evidence that stellate cells are also vital in hepatic regeneration, which needs to be confirmed by further investigations. Activated stellate cells express alpha- smooth muscle actin ( $\alpha$-SMA) which is used as a reliable marker for their detection ${ }^{[13]}$.

The present work was planned to trigger liver regeneration through an experimental model of $70 \%$ partial hepatectomy in male albino rats. This was done to investigate the role of HSCs and angiogenesis as demonstrated by immunohistochemistry for $\alpha$-SMA and VEGF respectively and its correlation with hepatocyte proliferation as detected by PCNA.

\section{MATERIAL AND METHODS}

\section{Animals}

The present study was carried out on forty male albino rats(4-6 months) with an average weight of 150-200 gm. The animals were obtained from the animal house of Kasr Al Aini, Faculty of Medicine, Cairo University. Following the guidelines for animal research issued by the National Institute of Health and approved by animal ethics committee, Cairo university .The rats were housed in hygienic cages , maintained on a standard pellet diet and were allowed free access to water.

\section{The rats were randomly divided into 5 groups}

- Group I: Included 8 rats which served as control group and were subjected to sham operation where midline laparotomy incision was done with gentle manipulation of the liver. The remaining four groups, included eight rats each, were subjected to $70 \%$ partial hepatectomy according the technique first described ${ }^{[14]}$. Then, the experimental animals were sacrificed by cervical dislocation at each of the following intervals after partial removal of the liver.

- Group II: Animals in this group were sacrificed three days postoperative.

- Groups III: Animals in this group were sacrificed seven days postoperative.
- Group IV: Animals in this group were sacrificed fourteen days postoperative.

- Groups V: Animals in this group were sacrificed twenty one days postoperative.

\section{Partial hepatectomy procedure}

All operations were carried out in the period between 9-12 am at room temperature.The animals were anesthesized by intramuscular injection of Ketamine (90 $\mathrm{mg} / \mathrm{kg})$ and Xylazine $(10 \mathrm{mg} / \mathrm{kg})^{[15]}$. A mid-line abdominal incision was done; and expose the liver. The left lateral lobe was first legated by 3-0 silk suture then removed. The median lobe was then legated by the same suture then removed. In this way, portions of the hepatic parenchyma ranging in extent from $65 \%$ to $75 \%$ of the total liver mass were removed while; the right lateral lobe and the small caudate lobe remained within the peritoneum. The peritoneal cavity was irrigated with procaine penicillin in a dose of 10,000-30,000 IU/KG. Finely, the abdomen was closed in two layers using $3 / 0$ silk suture. The abdominal wall muscles were sutured in one layer followed by the skin in the second layer. Disinfection with betadine was then used along the suture line ${ }^{[16]}$.

\section{Mortality and post-operative care}

Animals were left in airy room until they recovered from anesthesia and thereafter, they were housed in hygienic cages with suitable temperature, maintained on a standard pellet diet and were allowed free access to water. Two rats of the experimental animals died during the operation due to intraoperative bleeding caused by surgical injury to large blood vessel which could not be controlled. These rats were excluded from the study and replaced by other animals. No postoperative mortality was observed in the operated animals .

At the end time of each group, each rat was weighed (B) then sacrificed by cervical dislocation. A midline incision was done and the abdomen was opened. From each animal, the regenerated liver was dissected from the surrounding adhesions then removed and weighed (A). The liver weight to body weight ratios (LW/BWR) were calculated by dividing A to B multiplied by 100 .

Liver weight /body weight ratio $(\%)=\mathrm{A} / \mathrm{B} \times 100^{[17]}$.

\section{Histological study}

For light microscopy, the specimens of the liver were fixed in $10 \%$ formol saline and processed for paraffin sections which were cut into thin sections of 7 um thickness and were subjected to the following staining techniques:

1. Routine haematoxylin and $\operatorname{eosin}(\mathrm{H}$ and $\mathrm{E})$ staining ${ }^{[18]}$.

2. Immunohistochemical detection for proliferating cell nuclear antigen (PCNA), as a marker of proliferation. It was done by using monoclonal antibodies against $\mathrm{PCNA}^{[19]}$. 
3. Immunohistochemical detection for vascular endothelial growth factor (VEGF), as a marker of angiogenesis. It was done by using polyoclonal antibodies against VEGF ${ }^{[19]}$.

4. Immunohistochemical detection for alpha- smooth muscle actin ( $\alpha$-SMA), as a marker for HSCs activation. It was done by using monoclonal antibodies against $\alpha$-SMA ${ }^{[19]}$.

Both anti-PCNA and anti- $\alpha$-SMA are specific mouse monoclonal antibodies. Anti- VEGF antibody is a specific rabbit polyclonal antibody (lab vision corporation laboratories, USA). They are all specific antibodies that are reactive to human, mouse and rat tissues. They are supplied as prediluted antibody ready to use for staining formalin-fixed and paraffin-embedded tissues. They were stored at $2-8^{\circ} \mathrm{C}$.

The detection kit used in this study was Zymed LABSA system (Zymed Laboratories Inc, South San Francisco, CA.).

The contents of the kit were serum blocking solution (10\% non immune goat serum ), biotinylated secondary antibody, streptavidin peroxidase conjugate, $0.6 \%$ hydrogen peroxide $\left(\mathrm{H}_{2} \mathrm{O}_{2}\right)$ solution, concenterated substrate buffer, concenterated chromogen solution(DAB), haematoxylin solution and Histomount. Negative controls were done by omitting step of the primary antibody and its replacement by PBS.

\section{Morphometric study}

The Leica Qwin 500 image analyzer computer system (England) was applied. The image analyzer was first calibrated automatically to convert the measurement units (pixels) produced by the image analyzer program into actual micrometer units. It was used to measure the area percent of PCNA, VEGF and $\alpha$-SMA immunoreactions. For each group, ten measuring fields in each specimen were randomly selected, using objective lens of magnification 40 i.e. at total magnification of 400 .

\section{Statistical study}

The data obtained (LW/BWR, the area percent of PCNA, VEGF and $\alpha$-SMA) for all groups were expressed as means and standard deviations (SD) and subjected to statistical analysis then tabulated and represented graphically. One way ANOVA (Analysis of variance) was used to test the difference about mean values of measured parameters among groups, multiple comparisons between pairs of groups were performed using Post hoc range test; LSD (Low significant difference). For interpretation of the results of tests of significance, as regard the $\mathrm{P}$ value:

- $\quad$ Significant was adopted at $P<0.05$.

- Non significant was taken at $P>0.05$.

\section{RESULTS}

Morphometric and statistical results

(1) The mean liver weight/body weight ratio ( $L W / B W R)$

The mean LW/BWR showed a significant decrease $(P<0.05)$ in group II (three days postoperative) when compared to control. Gradual significant increase $(P<0.05)$ was observed in the remaining groups when compared to each other however, this increase in the mean LW/BWR in group III and IV was still significantly lower $(P<0.05)$ than the control level. On the other hand, no significant difference $(P>0.05)$ was found in group V (twenty one days postoperative) in relation to control.

\section{(2) The mean area percent of PCNA}

Statistical analysis was performed using ANOVA followed by post hoc range test. It revealed that there was a significant increase $(P<0.05)$ in the mean area \% of PCNA positive reaction in group II and III when compared to control although, there was a significant decrease in group III when compared to group II. On day 14 (group IV) and day 21 (group V), no statistical significant difference was noted when compared to control $(P>0.05)$.

\section{(3) The mean area percent of VEGF}

Statistical analysis showed that there was a significant increase $(P<0.05)$ in the mean area \% of VEGF positive reaction in group II and III when compared to control although, there was a significant decrease in group III when compared to group II. In group IV and group V, the mean area \% showed no statistical significant difference $(P>0.05)$ when compared to control group.

\section{(4) The mean area percent of $\alpha-S M A$}

Application of Post Hoc ANOVA test showed that there was a significant increase $(P<0.05)$ in the mean area \% of $\alpha$-SMA positive reaction in group II when compared to control. In group III, IV and V, no significant difference $(P>0.05)$ was noted as compared to control.

\section{Results of gross appearance of the liver}

Regarding the gross picture of the liver in group I (control rats), the liver appeared as multilobed solid organ composed of four distinct lobes, with smooth surfaces and dark red color. No gross changes were observed. In group II (animals sacrificed three days after PH), the liver appeared very pale when compared to control liver while, it appeared more or less normal with no pallor in group III (animals sacrificed seven days after PH) and, returned back to normal control color in group IV (animals sacrificed fourteen days after PH) and group V (animals sacrificed twenty one days after PH). Yellowish discoloration of the liver tissue was observed around the surgical stump in all 
experimental groups. Intraabdominal adhesions were seen between the liver and diaphragm, stomach, surrounding intestine and spleen. These adhesions were mild in group II and group V while, marked in group III and group IV.

\section{Light microscopic results}

\section{HandE}

\section{Group I (sham control)}

Histological examination of HandE stained sections from rat liver of group one revealed normal histological architecture of the liver. Hepatocytes were arranged in the form of branching and anastomosing cords radiated from the central veins and separated by blood sinusoids. The neatly arranged hepatocytes appeared polyhydral in shape with acidophilic granular cytoplasm and central rounded vesicular nuclei. Kupffer cells and endothelial cells were seen lining the blood sinusoids. The portal area was found at the periphery of the lobules and contained branches of the portal vein, hepatic artery and bile duct (Figure 1).

\section{Group II (animals sacrificed 3 days after PH)}

Histological examination of HandE stained sections from rat liver of group two revealed loss of the neatly arranged hepatocytes in radiating anastomosing plates with dilatation and congestion of the intervening blood sinusoids. The blood sinusoids appear numerous, distorted, wider and shorter with interrupted course when compared to control group which appear straight and relatively maintain constant sinusoidal width along the hepatic lobule. In some sections, hepatocytes appeared swollen, lightly stained nuclei and prominent nucleoli. The majority of hepatocytes showed vacuolations of their cytoplasm while other cells appear with discontinuous cell membrane, and karyolysis or pyknotic nuclei .Clusters of pale stained hepatocytes were observed and each cluster contained many pale stained cells (Figure 2). Mitotic figures were observed among the hepatocytes with different stages including metaphase, anaphase and telophase (Figure 3).

The portal area showed dilated congested portal vein branch, more branching of the bile duct which showed stratification of the lining epithelium, and also revealed the large number of flattened cells around the bile duct (Figure 4).

The sinusoidal endothelial cells were enlarged as compared to control . Large irregular cells with large oval or triangular nuclei and heterogenous cytoplasm (Kupffer cells) were widely distributed lining the blood sinusoids. Most of hepatocytes showed vesicular nuclei with prominent nucleoli or multiple nucleoli. Some hepatocytes appear with different stage of apoptosis, some cells show fragmented chromatin and deeply acidophilic cytoplasm, others cells appear with distorted nuclei with clumped or dispersed chromatin material (Figures 5 and 6).

\section{Group III (animals sacrificed 7 days after PH)}

The HandE stained sections from rat liver of group three revealed partial restoration of the hepatocyte arrangement in plates radiating from the dilated central vein (Figure 7).

Hepatocytes appeared swollen in most sections with acidophilic and granular cytoplasm. Flattened branched cells in wide space of disse could be seen (Figures 7 and 8). The portal area showed more branching bile duct with stratification of the lining epithelium and large number of flattened cells around the bile duct (Figure 8).

The intervening blood sinusoids were dilated, regularly arranged between the hepatocytes plates and lined by enlarged endothelial cells which appeared detached in some sections. Many Kupffer cells with condensed heterogenous cytoplasm and dark nuclei were also seen (Figures 7 and 8).

\section{Group IV (animals sacrificed 14 days after PH)}

Microscopic examination of the HandE stained sections from rat liver of group four revealed restoration of the histological architecture of the liver. Hepatocytes were arranged in branching anastomosing cords radiating from the central vein which was dilated and congested (Figure 9).

Almost all hepatocytes were more or less normal. The nuclei appeared vesicular with prominent nucleoli and more condensation of the nuclear chromatin than the previous two groups. Cytoplasm was acidophilic and granular. The flattened branched cells could be seen. Small bile duct branch was appeared surrounded by large number of cells with oval nuclei (Figure 10).The portal vein appeared dilated and congested. The intervening blood sinusoids were dilated and lined with proliferating endothelial cells and Kupffer cells (Figures 9 and 10).

\section{Group V (animals sacrificed 21 days after PH)}

Histological examination of the HandE stained sections from rat liver of group five revealed preserved histological architecture of the liver. Hepatocytes were arranged in anastomosing plates radiating from the central vein (Figure 11).Hepatocytes were apparently normal. The nuclei were vesicular having prominent nucleolei and more condensed nuclear chromatin than in group II and III. Cytoplasm was acidophilic and granular (Figure 11).

The portal area was infiltrated with mononuclear cells as well; these infiltrates were noted among the hepatocytes as well as developing hepatic cords (proliferating hepatocytes) nearby the cellular infiltration were appeared. The flattened spindle cells and the branched cells with oval nuclei could be seen(Figure 12). The intervening blood sinusoids were dilated and congested. Flat endothelial cells and Kupffer cells were seen lining the blood sinusoids. Also, dilatation and congestion of the portal vein branch (Figures 11,12). 


\section{PCNA immunostaining}

\section{- Group I}

Immune-histochemically stained sections from rat liver of control group showed scattered hepatocytes with positive nuclear immunoreactions localized in the region of the central vein (V) and the portal tract (Figure 13).

\section{- Group II}

Numerous hepatocytes with positive nuclear immunoreactions were detected all over the section, around the central vein and the portal tract (Figure 14).

\section{- Group III}

Positive nuclear immunoreaction for PCNA was detected in few hepatocytes around the central vein and near to the portal tract (Figure 15).

\section{- Group IV}

Very few hepatocytes with positive nuclear immunoreactions were observed near to the central vein and portal tract (Figure 16).

\section{- Group V}

The positive nuclear immunoreactivity was limited to very few hepatocytes around central vein and near to the portal tract (Figure 17).

\section{VEGF immunostaining}

\section{- Group I}

The VEGF positive cytoplasmic immunoreaction was limited to the pericentral hepatocytes. The hepatocytes around portal tract showed negative immunoreaction (Figure 18).

\section{- Group II}

Diffuse VEGF positive cytoplasmic immunoreactions were shown in all hepatocytes around central vein and those around portal tract (Figure 19).

\section{- Group III}

Immune-histochemcally stained sections showed positive cytoplasmic immunoreaction for VEGF limited to midzonal hepatocytes and some cells around the central vein. Hepatocytes around the portal tract showed negative immunoreaction (Figure 20).

\section{- Group IV}

Few hepatocytes around central vein showed positive cytoplasmic immunoreactivity and those around portal tract showed negative immunoreaction (Figure 21).

\section{- Group V}

Positive VEGF cytoplasmic immunoreaction was detected in few hepatocytes around central vein and those around portal tract showed negative immunoreaction (Figure 22).

\section{3. $\alpha-S M A$ immunostaining}

\section{- Group I}

Immune-histochemcally stained sections from rat liver of control group showed positive cytoplasmic immunoreactivity for $\alpha$-SMA in the cytoplasm of the smooth muscles of the vessels wall. The surrounding hepatocytes showed negative immunoreaction (Figure 23).

\section{- Group II}

Spindle shaped cells with positive cytoplasmic immunoreaction for $\alpha$-SMA were observed around the blood sinusoids (Figure 24). Also, flat and branched cells with positive cytoplasmic immunoreaction were seen among the vacuolated hepatocytes (Figures 25,26).

\section{- Group III}

The $\alpha$-SMA positive cytoplasmic immunoreactivity was limited to the smooth muscles of the wall of central vein as well as the portal vessels (Figure 27).

\section{- Group IV}

The immunoreaction for $\alpha$-SMA was localized in the smooth muscles of the central vein and the vessels wall in the portal tract (Figure 28).

\section{- Group V}

$\alpha$-SMA immunohistochemical staining of sections from rat liver of group five showed positive cytoplasmic immunoreaction in the smooth muscles of the central vein and the portal vessels (Figure 29). 

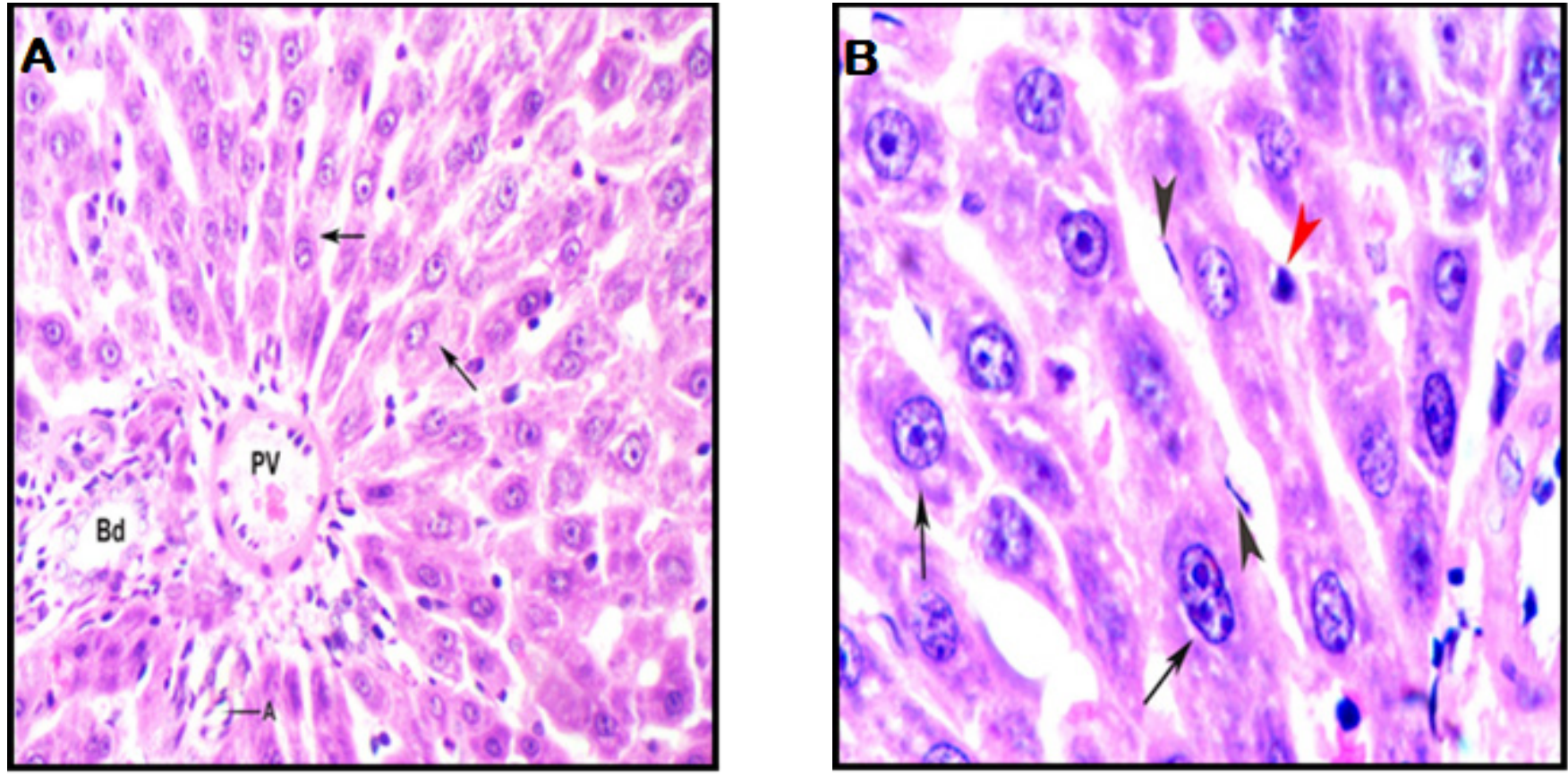

Fig. 1: A Photomicrographs of a section in rat liver of control group (A) showing regularly arranged hepatocyte plates radiated from the central vein and the portal tract. The hepatocytes have rounded vesicular nuclei with prominent nucleoli and acidophilic granular cytoplasm (black arrows). The blood sinusoids are regularly arranged and lined by endothelial cells with flattened nuclei (black arrowheads). The portal tract shows branches from the portal vein (PV), bile duct (Bd) and hepatic artery (A). (B) Showing the endothelial cells (black arrowheads) and Kupffer cell (red arrowhead) lining the blood sinusoid. Hepatocytes appear with acidophilic granular cytoplasm and vesicular nuclei with prominent nucleoli (black arrows). (HandE. A X400-B X1000)
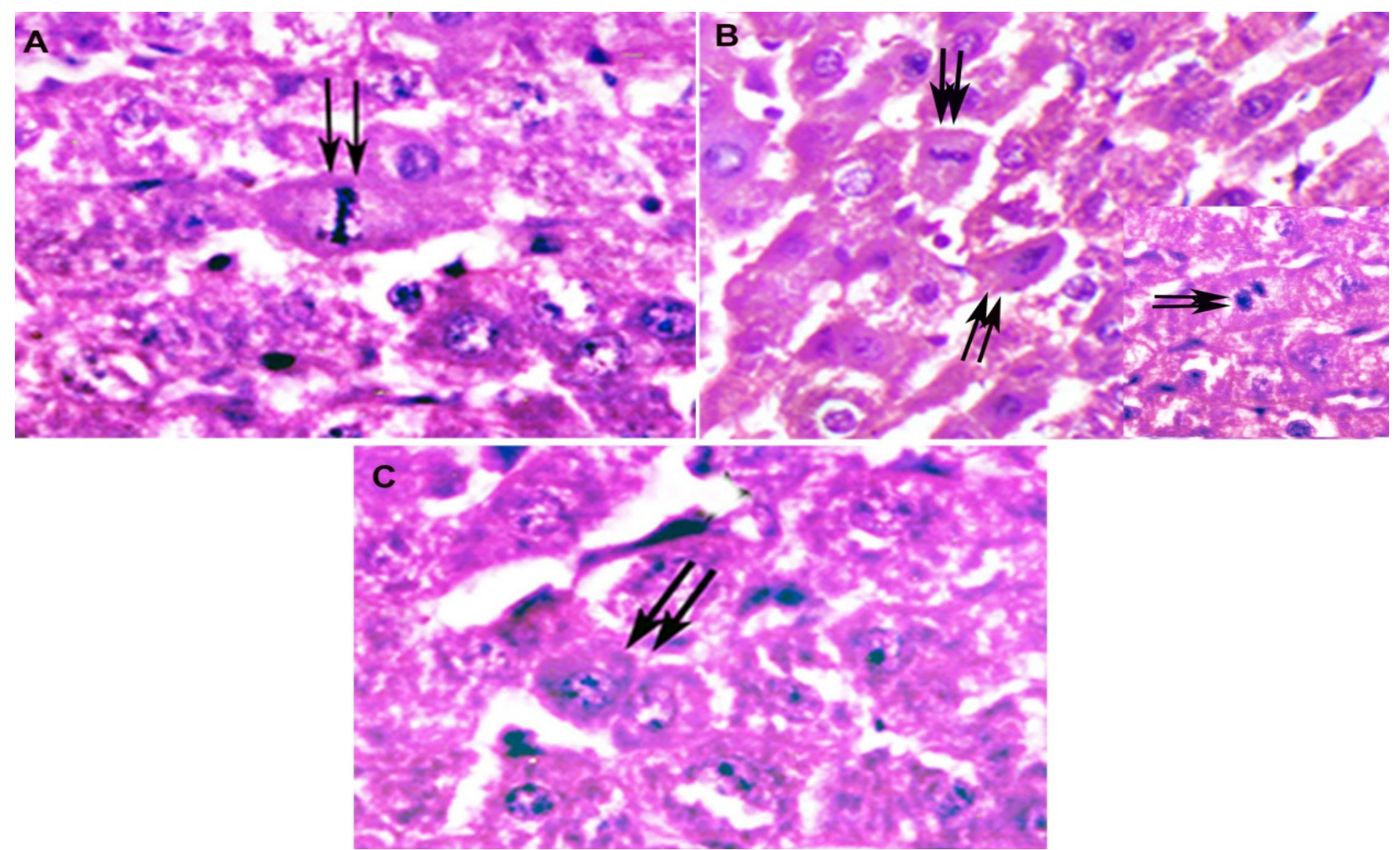

Fig. 2: Photomicrographs of a section in rat liver of group two(A)revealing distorted hepatocytes plates with disturbance of the intervening blood sinusoids (S). Some hepatocytes appear swollen with enlarged, lightly stained nuclei and prominent nucleoli (black arrows), while other cells appear with discontinuous cell membrane, and karyolysis or pyknotic nuclei (green arrow).Marked hypertrophy of Kupffer cells (red arrowheads) with engorged heterogeneous cytoplasm and condensed nuclei within the blood sinusoids which lined by endothelial cells (black arrowheads). (B) revealing cluster of vacuolated hepatocytes with pale cytoplasm (zigzag arrows) with dilatation and congestion of blood sinusoids (stars) which appear numerous, distorted, wide and short with interrupted course. (A:HandE X1000-B: HandE X400) 

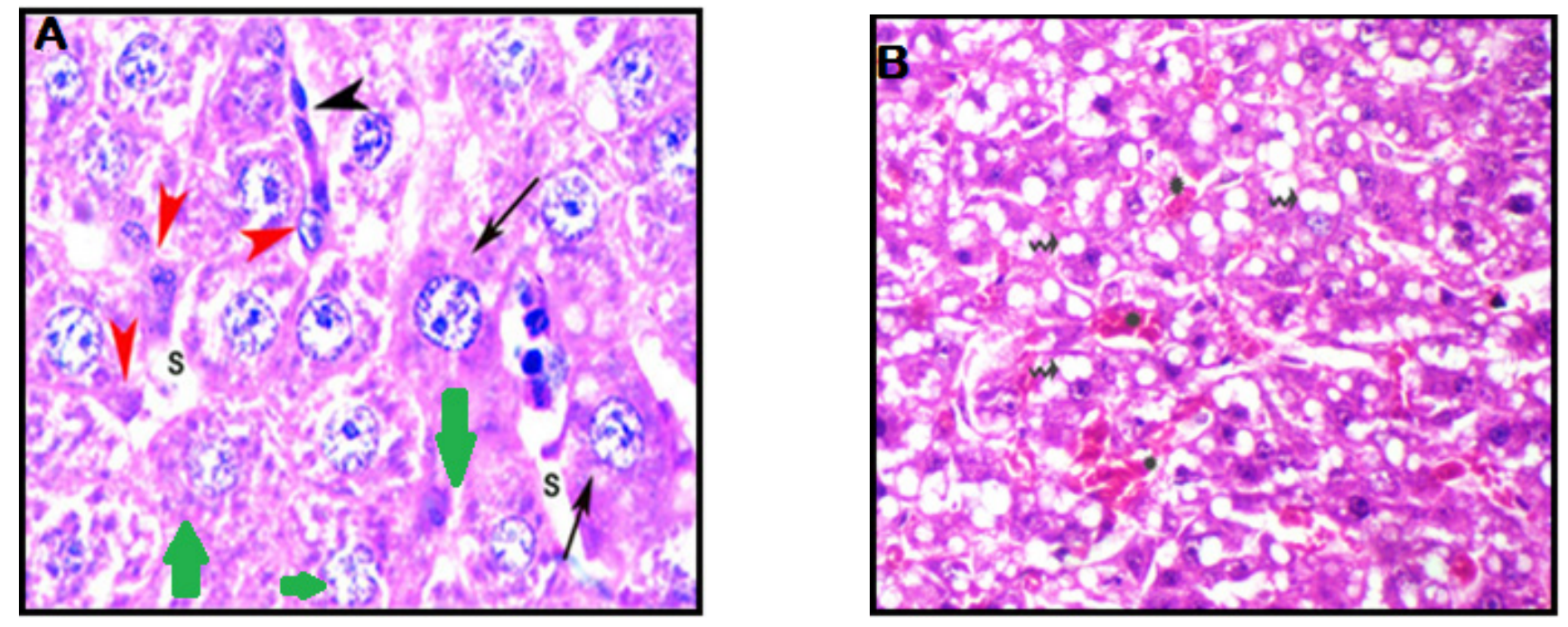

Fig. 3: photomicrographs of a section in rat liver of group two showing different stages of mitotic figures (double arrows). A: Metaphase stage. B: Metaphase and anaphase stages. C: Two daughter cells in telophase stage. (HandE. X400)
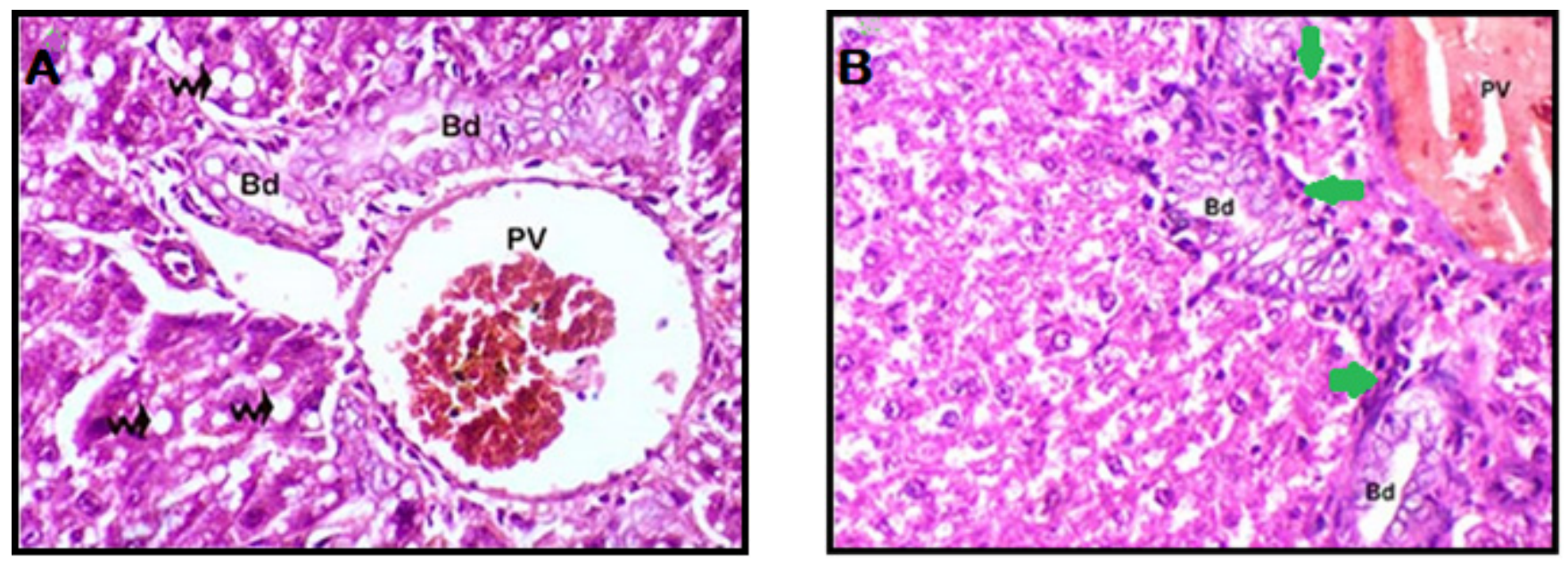

Fig. 4: Photomicrographs of a section in rat liver of group two, in the portal region, (A)revealing dilatation andcongestion of the portal vein branch (PV) and more branching of the bile ducts (Bd) with stratification of the lining epithelium. Notice, the vacuolated hepatocytes (zigzag arrows). (B) revealing marked increased branching of the bile ducts $(\mathrm{Bd})$ with stratification of the lining epithelium . Notice, the large number of flattened cells around the bile duct(green arrow). (HandE. X400)

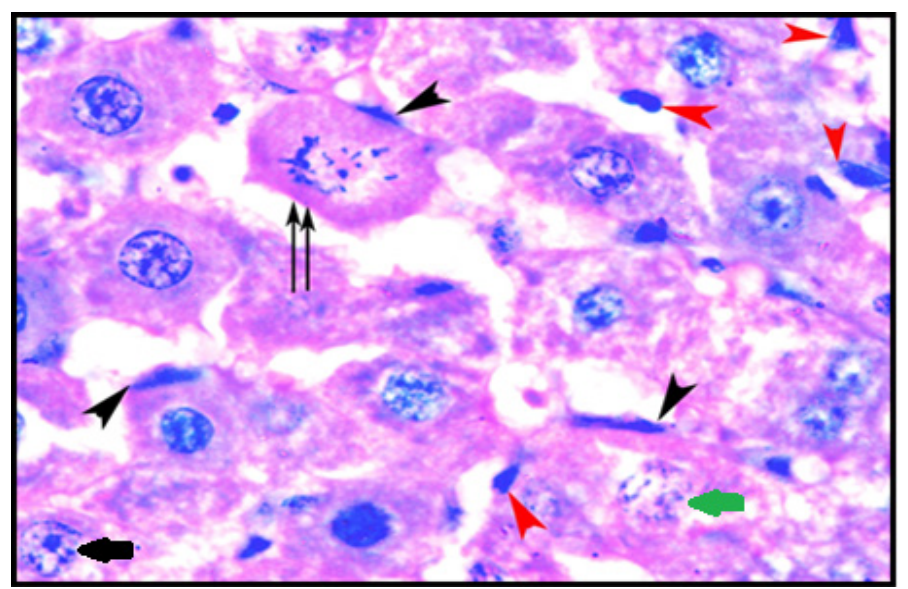

Fig. 5: A photomicrograph of a section in the rat liver of group two showing prominent endothelial cells (black arrowheads) lining the blood sinusoids. Kupffer cells with dark nuclei (red arrowheads) are also seen. Some hepatocyte appear with distorted nuclei and clumped chromatins(black arrow), while other cell shows fragmented chromatin(green arrow). Notice, the anaphase stage (double arrows). (HandE. X1000) 

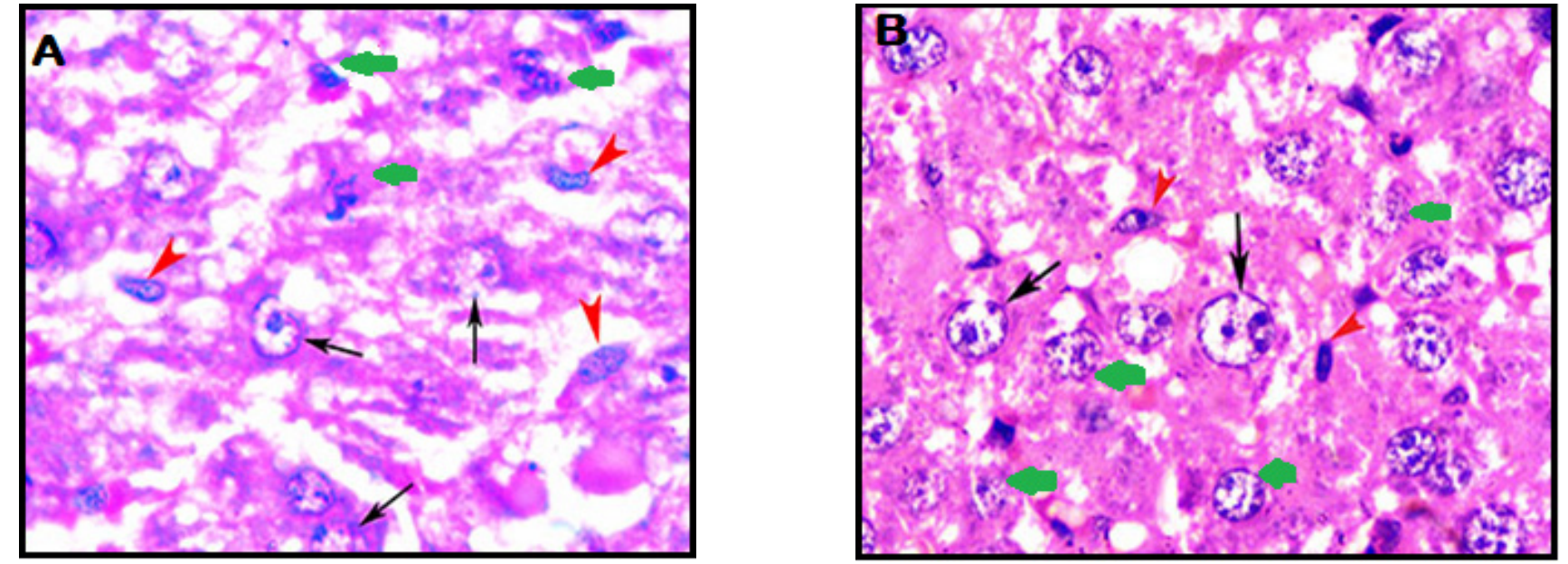

Fig. 6: Photomicrographs of a section in the rat liver of group two (A) showing irregular Kupffer cells with large oval pale nuclei and heterogenous cytoplasm (red arrowheads) lining the blood sinusoids. The hepatocytes appear with different stage of apoptosis, some cells show fragmented chromatin and deeply acidophilic cytoplasm(green arrow),others show nuclei with dispersed chromatin material and prominent nucleoli (black arrows) .(B) showing some hepatocytes have vesicular nuclei with prominent nucleoli or multiple nucleoli(black arrows),others show nuclei with fragmented chromatin(green arrow). Kupffer cells with dark nuclei (red arrowheads) are also seen. (HandE. X1000)

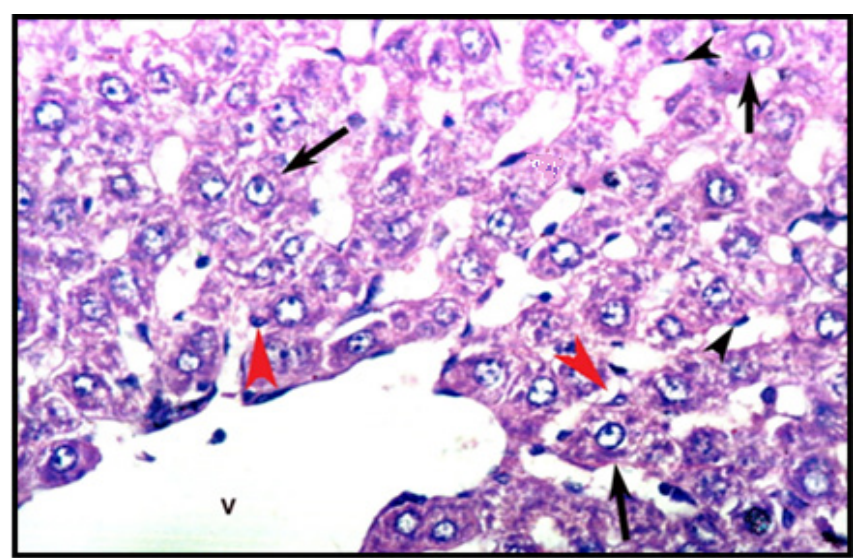

Fig. 7: Photomicrographs of a section in rat liver of group three showing regular arrangement of hepatocytes in anastomosing and branching cords radiating from the dilated central vein (V). The blood sinusoids (S) are dilated, regularly arranged and lined by flattened endothelial cells (black arrowheads) and kpuffer cells (red arrowheads) with condensed cytoplasm.Swollen hepatocytes around central vein (V) with large vesicular nuclei and acidophilic granular cytoplasm are seen (black arrows). Notice, the fibroblast like cells (green arrow). (HandE X 400)
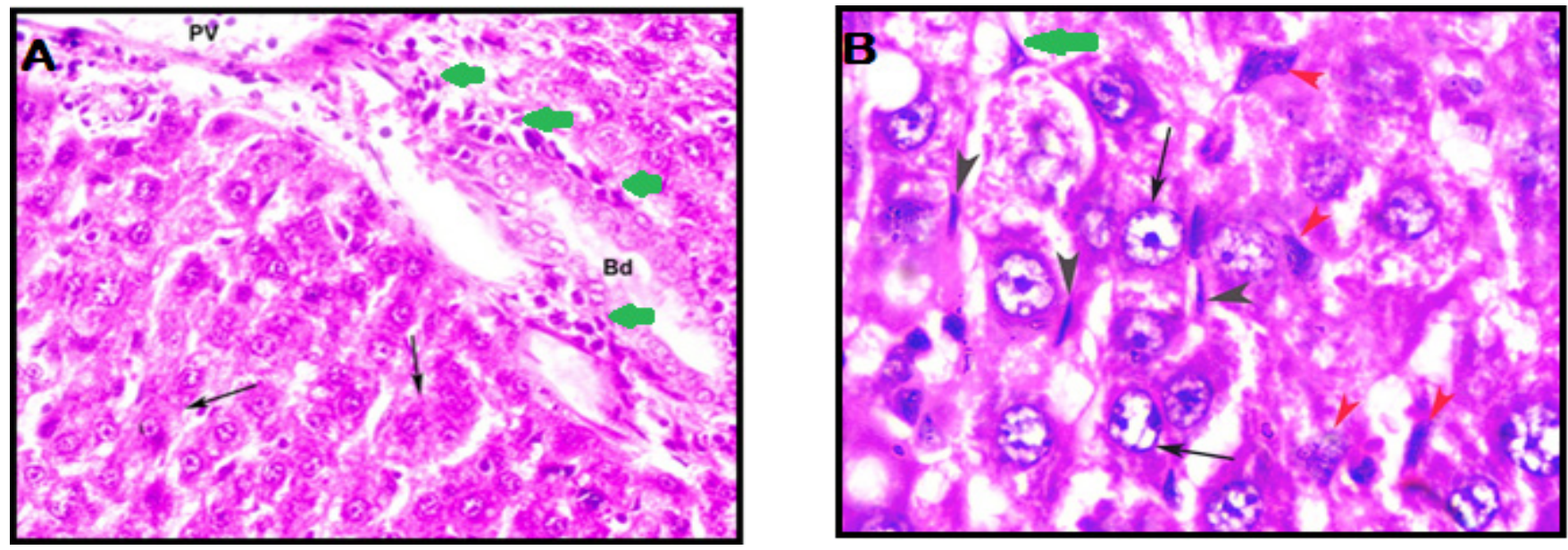

Fig. 8: Photomicrographs of a section in rat liver of group three, in the portal region,(A) revealing more branching bile duct (Bd) with stratification of the lining epithelium and large number of flattened cells around the bile duct(green arrow). The wide plates are with swollen hepatocyte ,acidophilic vacuolated cytoplasm and pale nuclei (black arrows).(B) revealing enlarged endothelial cells (black arrowheads) and many Kupffer cells with heterogenous cytoplasm and dark nuclei, lining blood sinusoids (red arrowheads). The hepatocytes nuclei appear lightly stained with dispersed chromatin and prominent nucleoli (black arrows). Notice, the flattened branched cell (green arrow) in wide space of disse. (HandE . A X400-B X1000) 


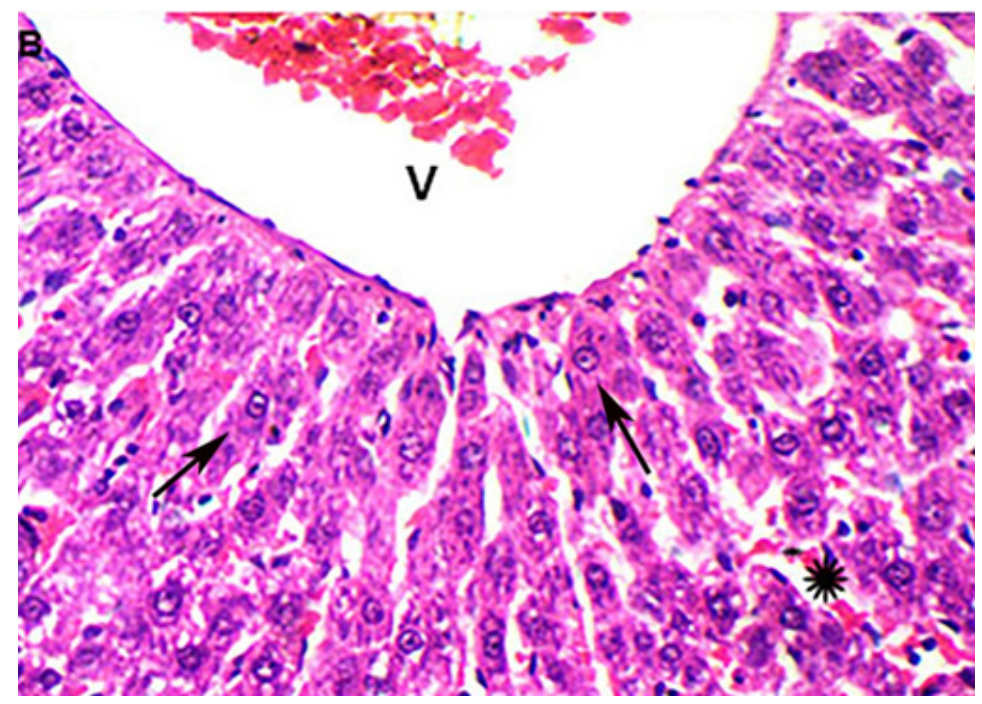

Fig. 9: Photomicrographs of a section in rat liver of group four showing regular arrangement of hepatocytes in radiating, anastomosing and branching cords Hepatocytes are apparently normal with acidophilic cytoplasm and large vesicular nuclei (black arrows) while, the central vein (V) is dilated and congested. The intervening blood sinusoids show some congestion (star). (HandE X400)
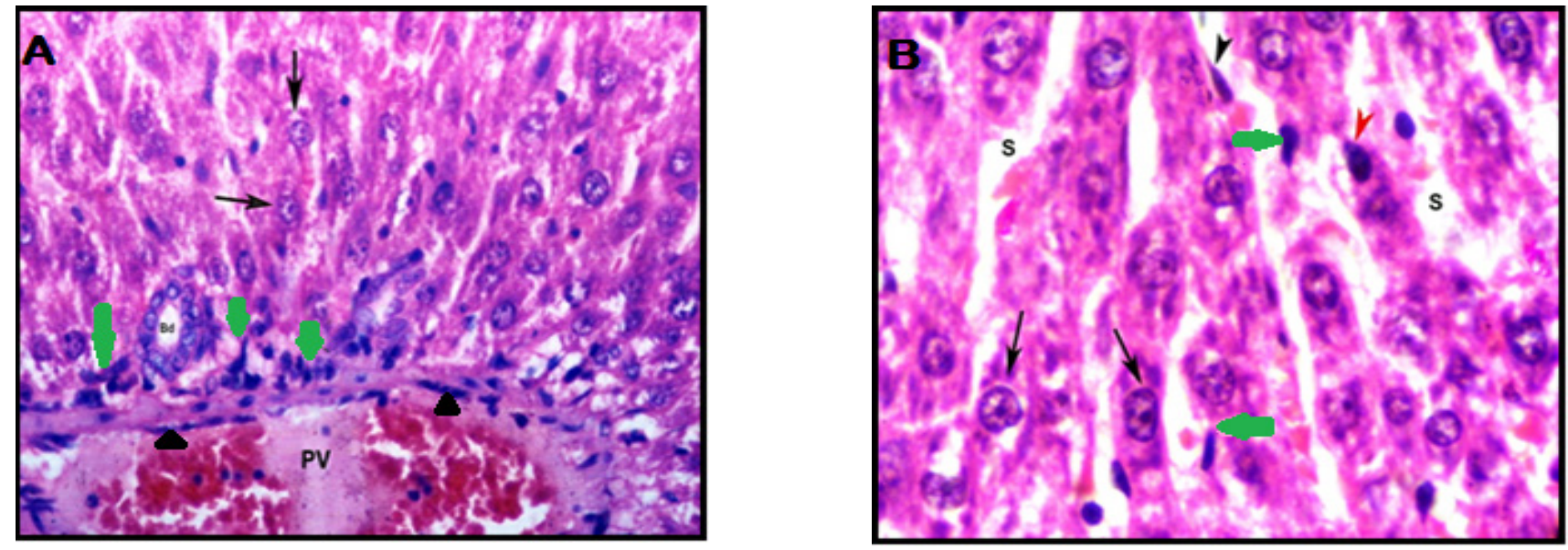

Fig. 10: Photomicrograph of a section in rat liver of group four, in the portal region,(A) showing portal vein branch (PV) is dilated and congested with endothelial cells proliferation(arrow head). Small bile duct branch is seen (Bd) surrounded by large number of cells with oval nuclei(green arrow).Hepatocytes appear with acidophilic cytoplasm and vesicular nuclei (black arrows). (B) showing regular arrangement of hepatocytes in plates separated by dilated blood sinusoids (S) lined by flat endothelial cells (black arrowheads) and Kupffer cells (red arrowheads). The hepatocyte with vesicular nuclei (black arrows). Notice, the flattened branched cells(green arrow). (HandEA X400-B X1000)
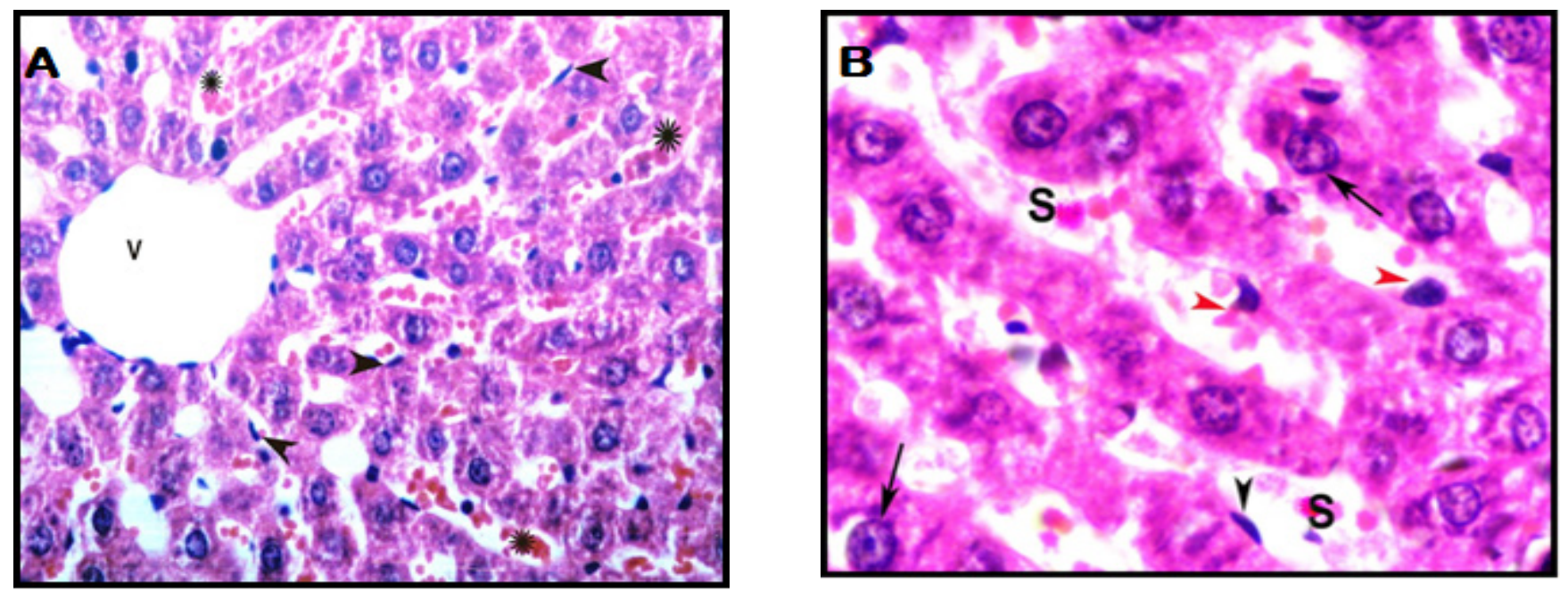

Fig. 11: A photomicrograph of a section in rat liver of group five (A) showing regularly intervened dilated and congested blood sinusoids (stars). Endothelial cells (black arrowhead) are seen lining the blood sinusoids. (B) showing regularly arranged hepatocyte plates, separated by dilated blood sinusoids (S). Kupffer cells (red arrowhead) and endothelial cells (black arrowheads) are lining blood sinusoids. Hepatocytes appear with average size and acidophilic granular cytoplasm and vesicular nuclei with condensed chromatin and prominent nucleoli (black arrows). (HandE. A X400-B X1000) 

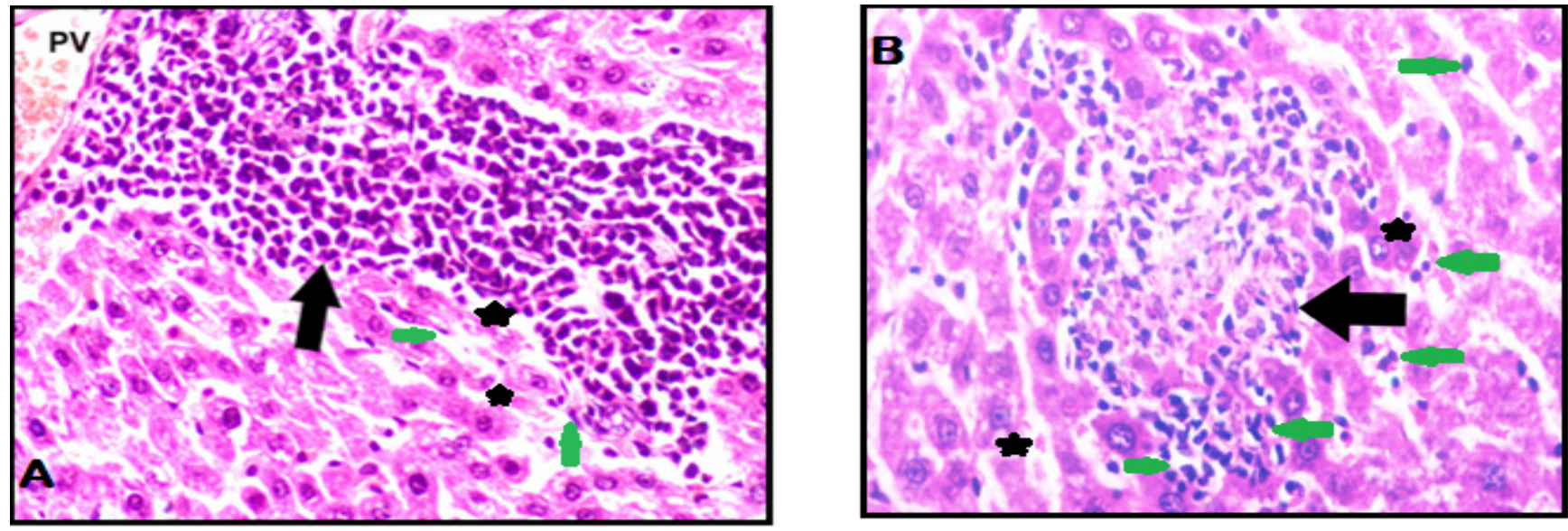

Fig. 12: A photomicrograph of a section in rat liver of group five (A) showing congestion of the portal vein branch (PV), the portal area infiltrated with mononuclear cells (black arrow) and developing hepatic cords(proliferating hepatocytes)(star)nearby the cellular infiltration. Notice, the flattened spindle cells (green arrow) (B) showing an island of mononuclear cell infiltration among the hepatocytes (black arrow) and developing hepatic cords (star). Notice, the branched cells with oval nuclei (green arrow). (H and E. X400)

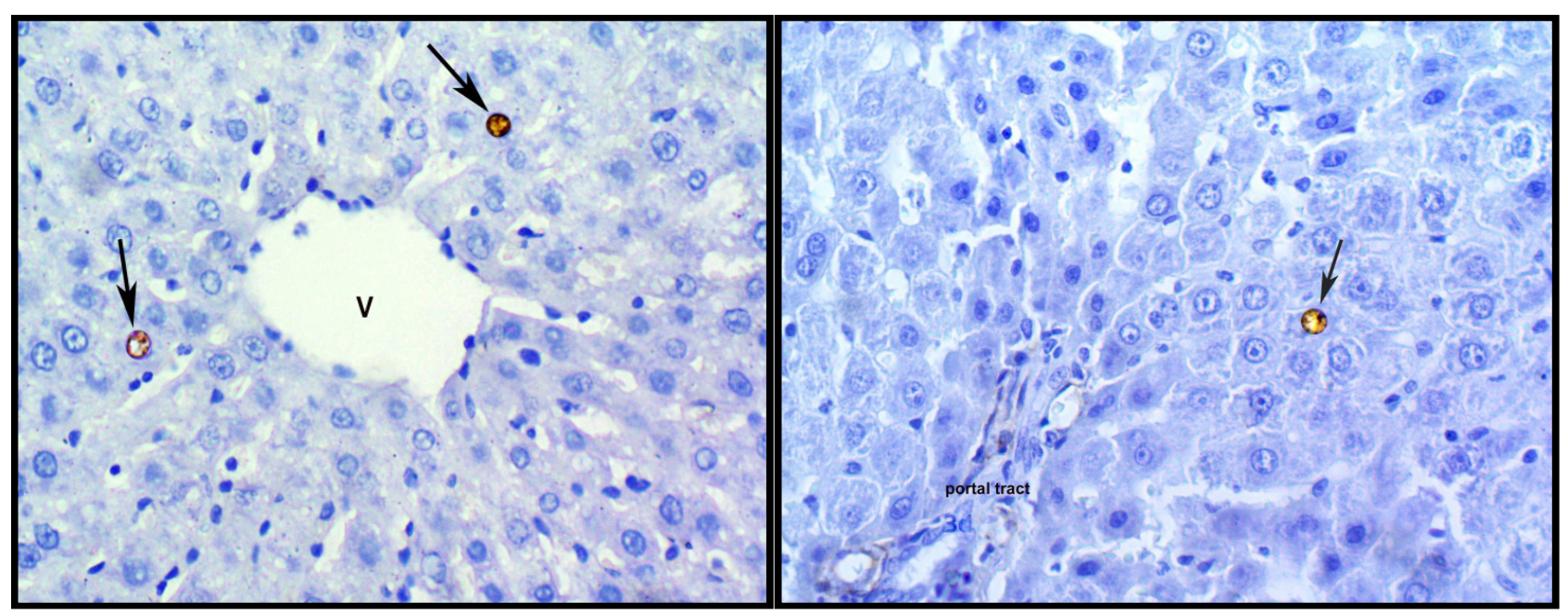

Fig. 13: (A) photomicrograph of a section in rat liver of control group positive nuclear immunoreaction near to the central vein (V).(B) showing one hepatocyte with positive nuclear immunoreaction near to the portal tract (black arrow). (PCNA immunoreactivity. X400)

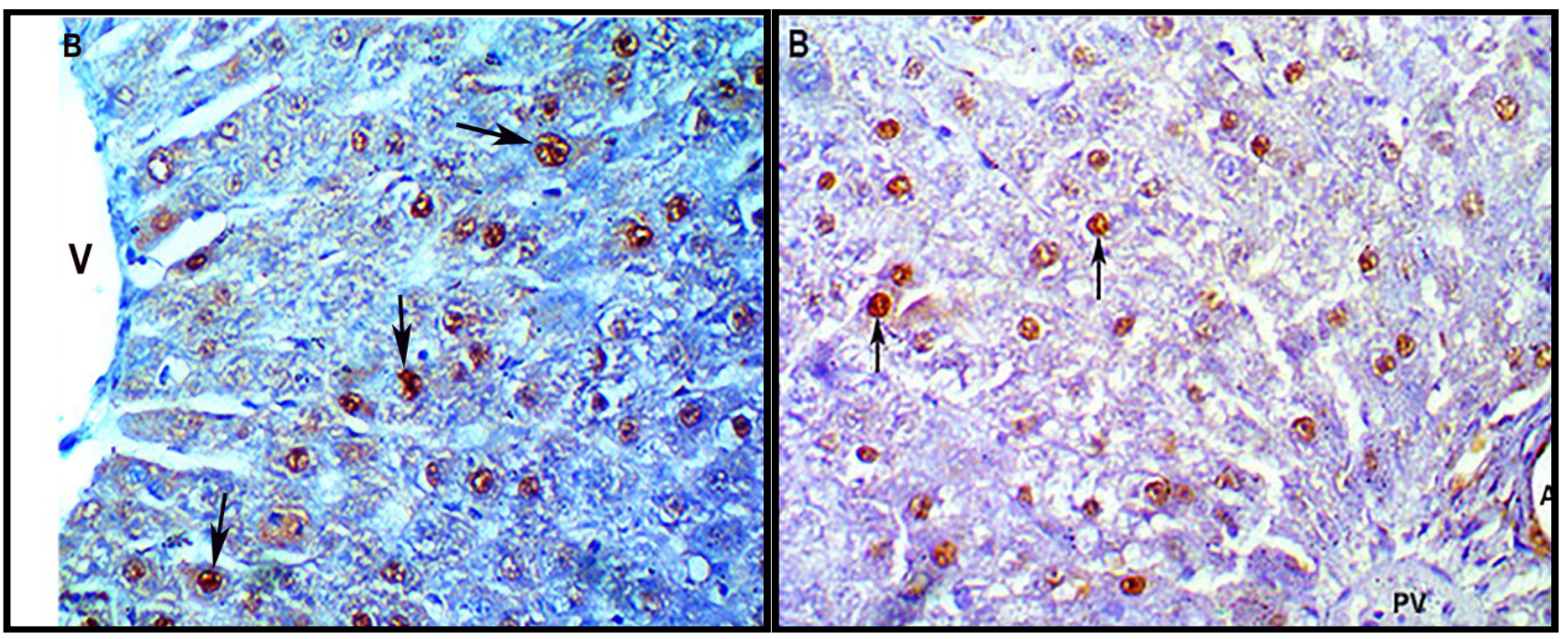

Fig. 14: photomicrographs of a section in rat liver of group two immunostained for PCNA (A) showing positive nuclear immunoreaction of most hepatocytes (black arrows) around the central vein (V).(B) showing positive nuclear immunoreaction of almost all hepatocytes (black arrows) around the portal vein (PV) and hepatic artery (A). ( PCNA immunoreactivity X400) 


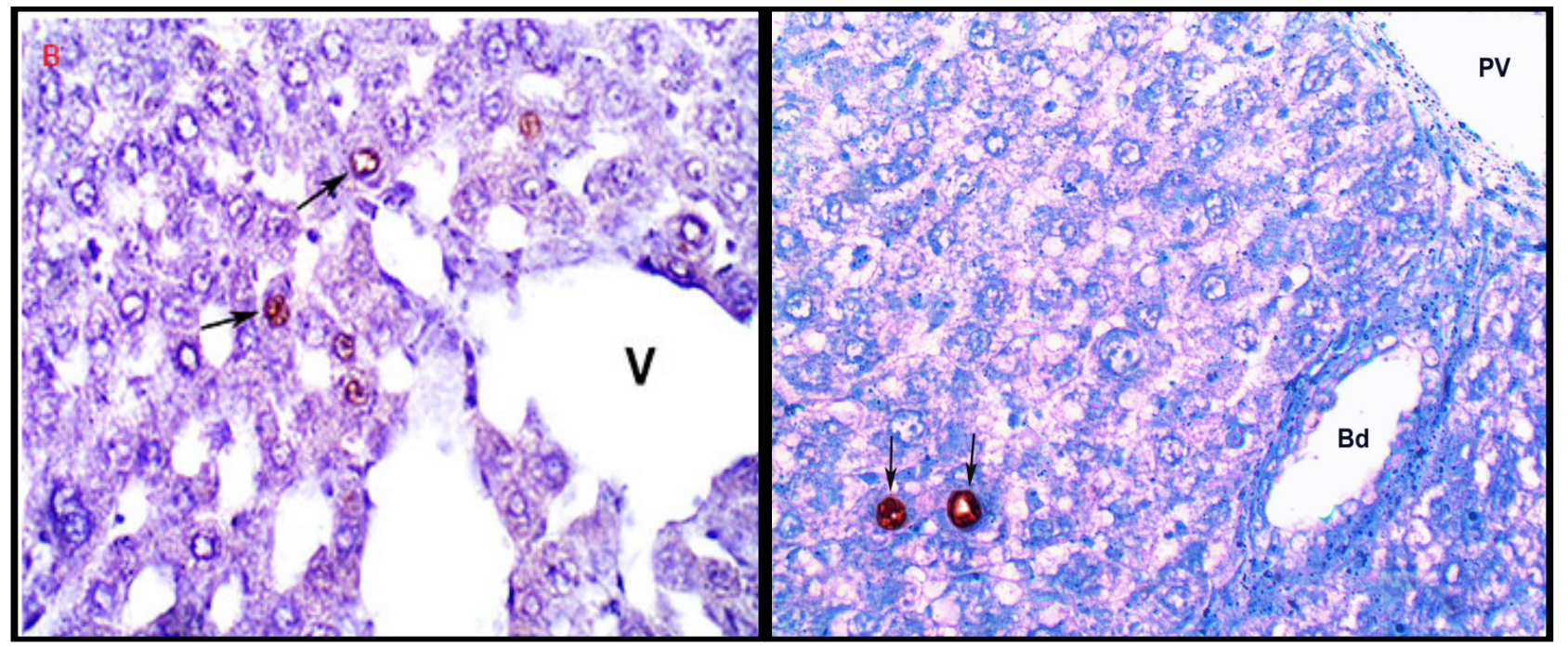

Fig. 15: photomicrographs of a section in rat liver of group three immunostained for PCNA(A) showing positive nuclear immunoreaction in only few hepatocytes around the central vein(V) (black arrows).(B) showing very few hepatocytes near the portal area, with positive nuclear immunoreaction (black arrows). ( PCNA immunoreactivity X400)

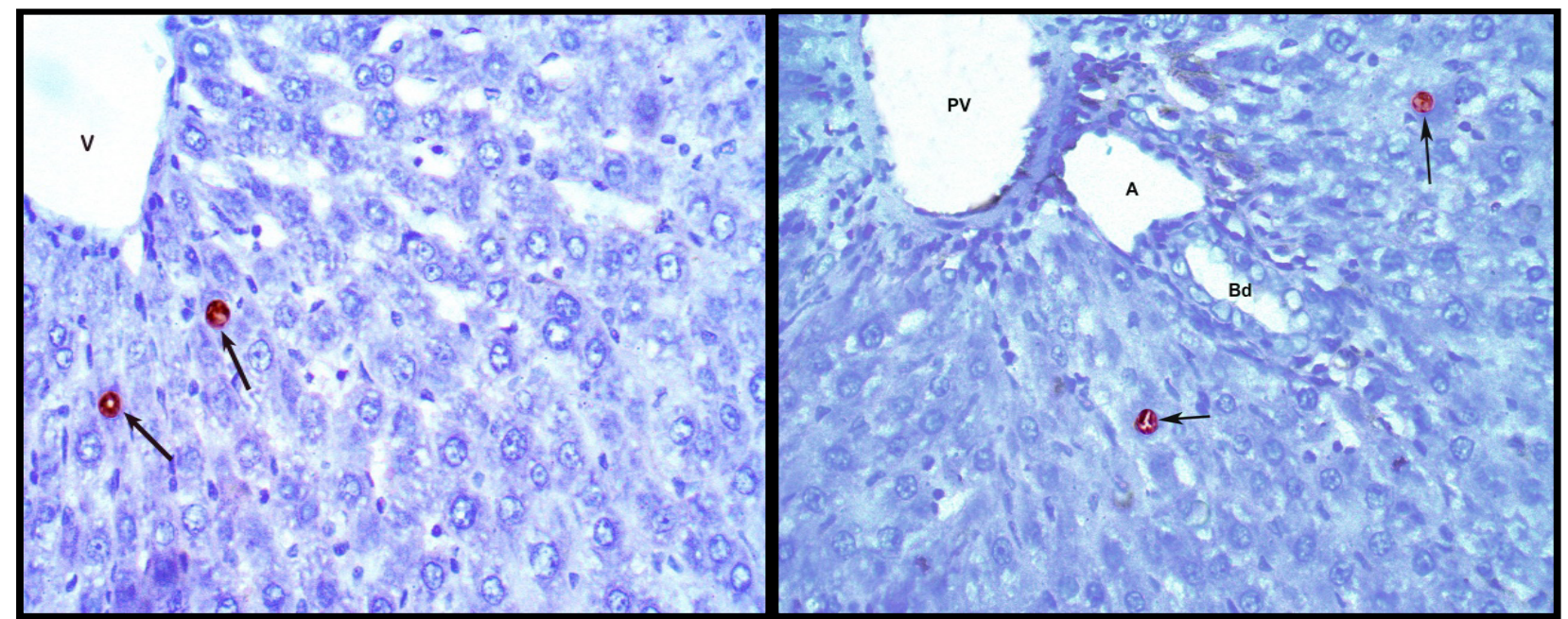

Fig. 16: A photomicrograph of a section in rat liver of group four(A) showing very few hepatocytes near the central vein (V) (black arrows), with positive nuclear immunoreaction for PCNA.(B) showing only two immunostained hepatocyte nuclei for PCNA, around the portal area (black arrows). (PCNA immunreactivity X400)

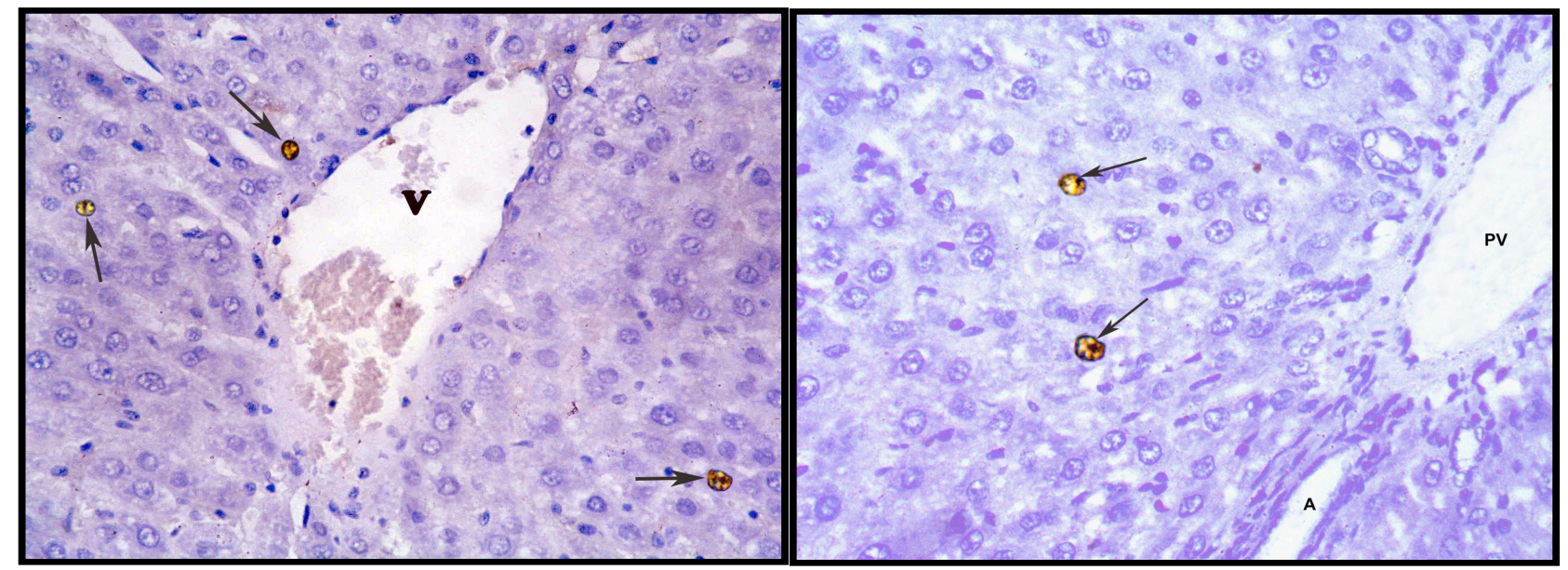

Fig. 17: A photomicrograph of a section in rat liver of group five(A) showing few dispersed hepatocytes' nuclei (black arrows), which are positive for PCNA, around the central vein (V).(B) showing only two hepatocytes with positive nuclear immunoreaction (black arrows) close to the portal area, showing the portal vein (PV) and hepatic artery (A) branches. (PCNA immunoreactivity. X400) 


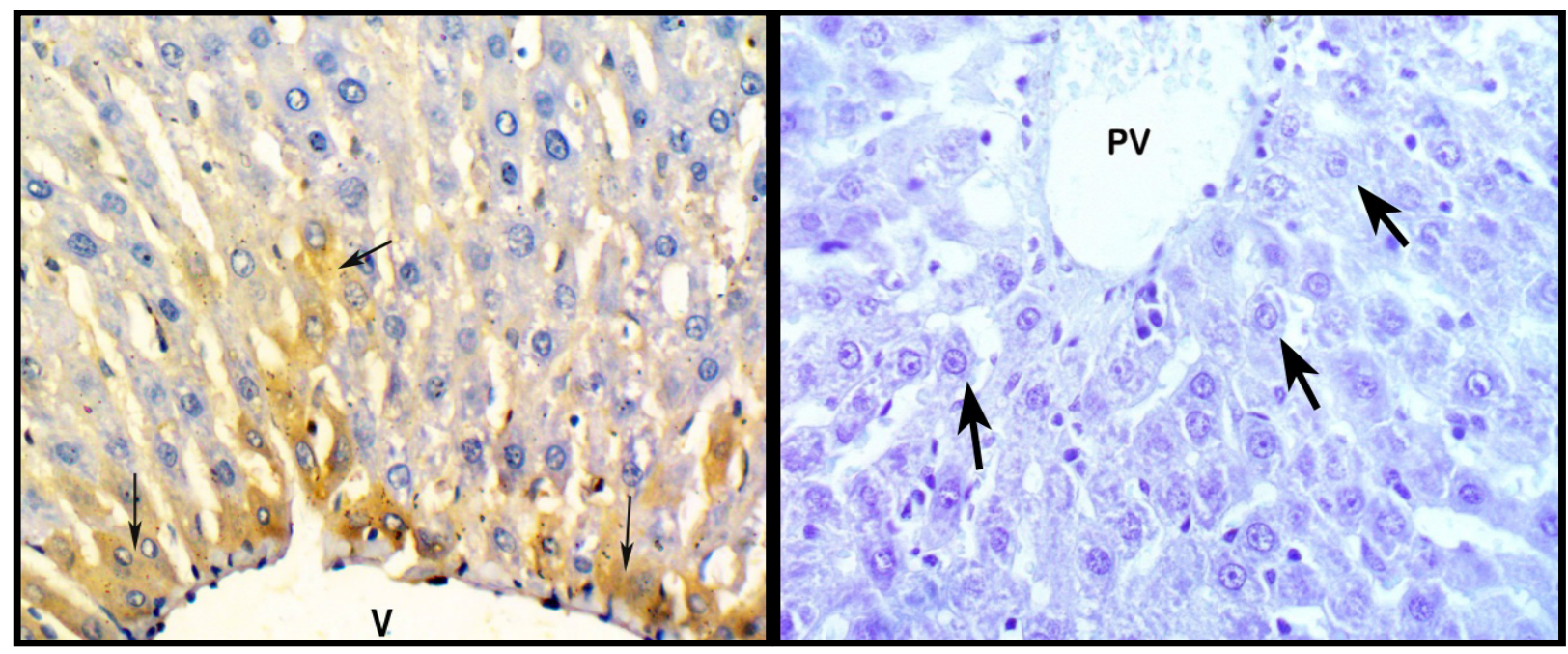

Fig. 18: A photomicrograph of a section in rat liver of control group(A) showing positive cytoplasmic immunostaining for VEGF in most hepatocytes around the central vein (V). Some nearby hepatocytes also show positive immunostaining (black arrows).(B) showing negative cytoplasmic reaction of all hepatocytes (black arrows) around the portal tract. (VEGF immunoractivity, X400)

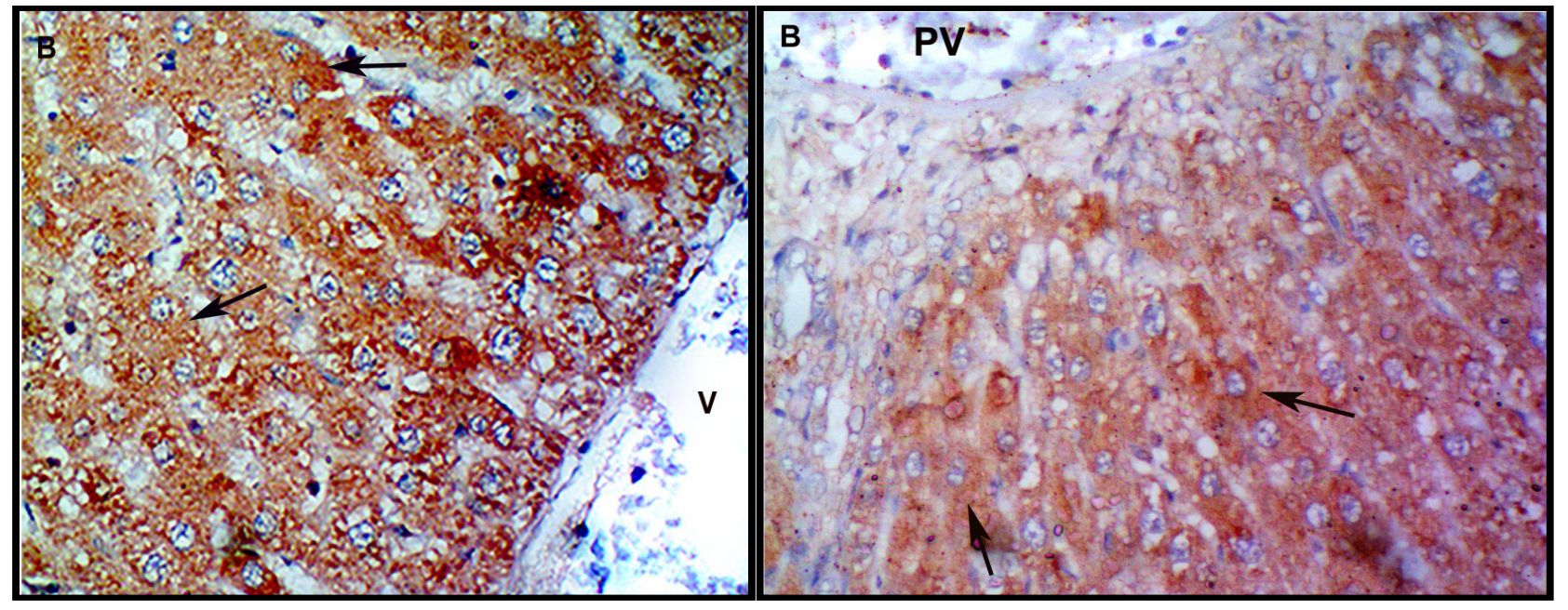

Fig. 19: photomicrographs of a section in rat liver of group two immunostained for VEGF (A) revealing diffuse positive cytoplasmic immunoreaction of all hepatocytes (black arrows) around the central vein (V).(B) revealing diffuse positive cytoplasmic immunoreaction of all hepatocytes around the portal tract (black arrows). (VEGF immunoreactivity X400)

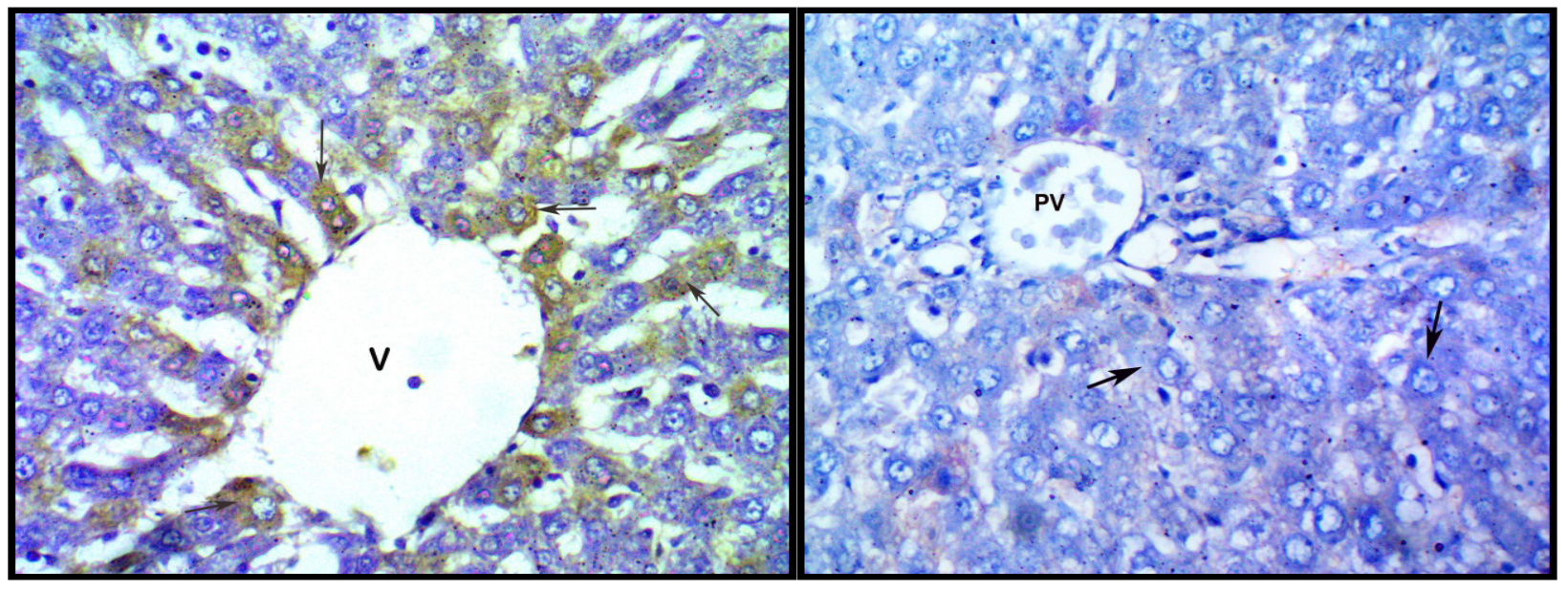

Fig. 20: A photomicrograph of a section in rat liver of group three immunostained for VEGF (A)showing midzonal hepatocytes and those around central vein (V) with positive immunoreaction(black arrows).(B) showing the portal area and the surrounding hepatocytes (black arrows) with negative cytoplasmic immunoreaction for VEGF. (VEGF immunoreactivity. X400) 


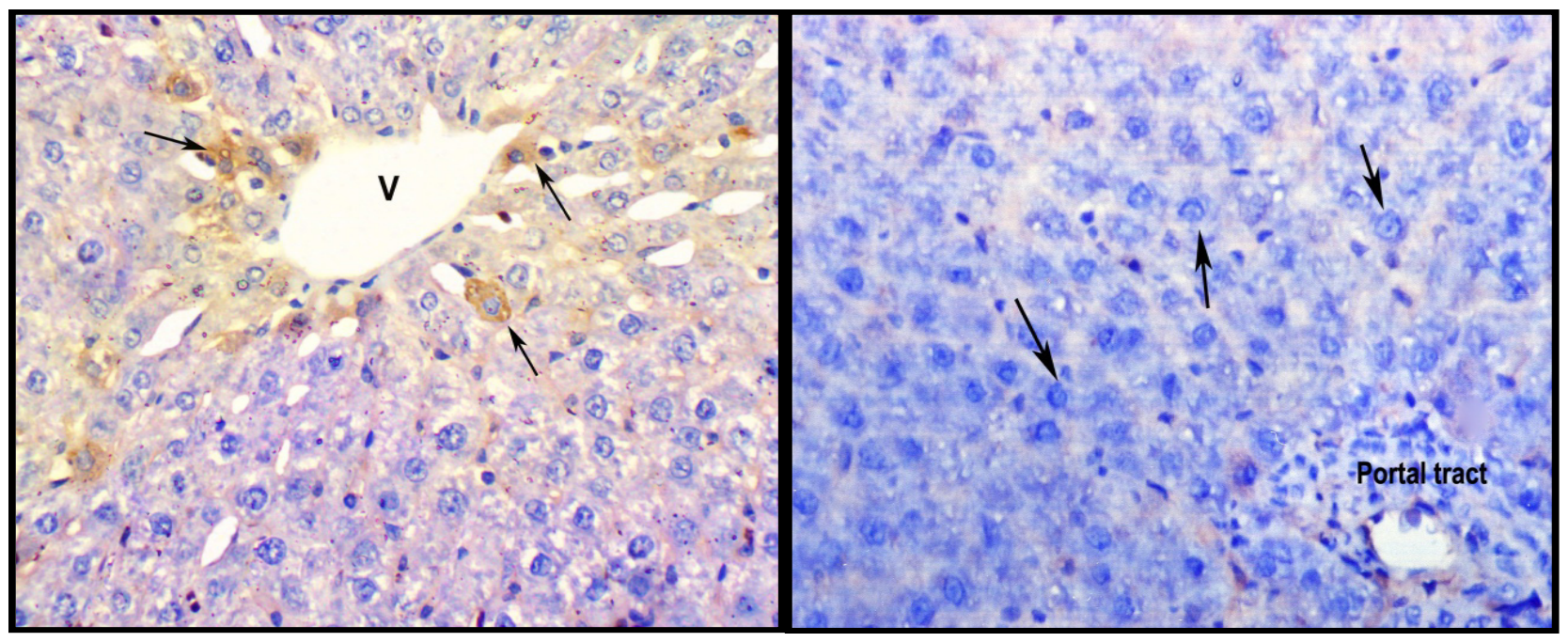

Fig. 21: A photomicrograph of a section in rat liver of group four (A)showing positive cytoplasmic immunoreaction for VEGF in few hepatocytes mostly around central vein (black arrows). (B) showing hepatocytes around portal tract with negative cytoplasmic immunoreaction for VEGF (black arrows). (VEGF immunreactivity X400)

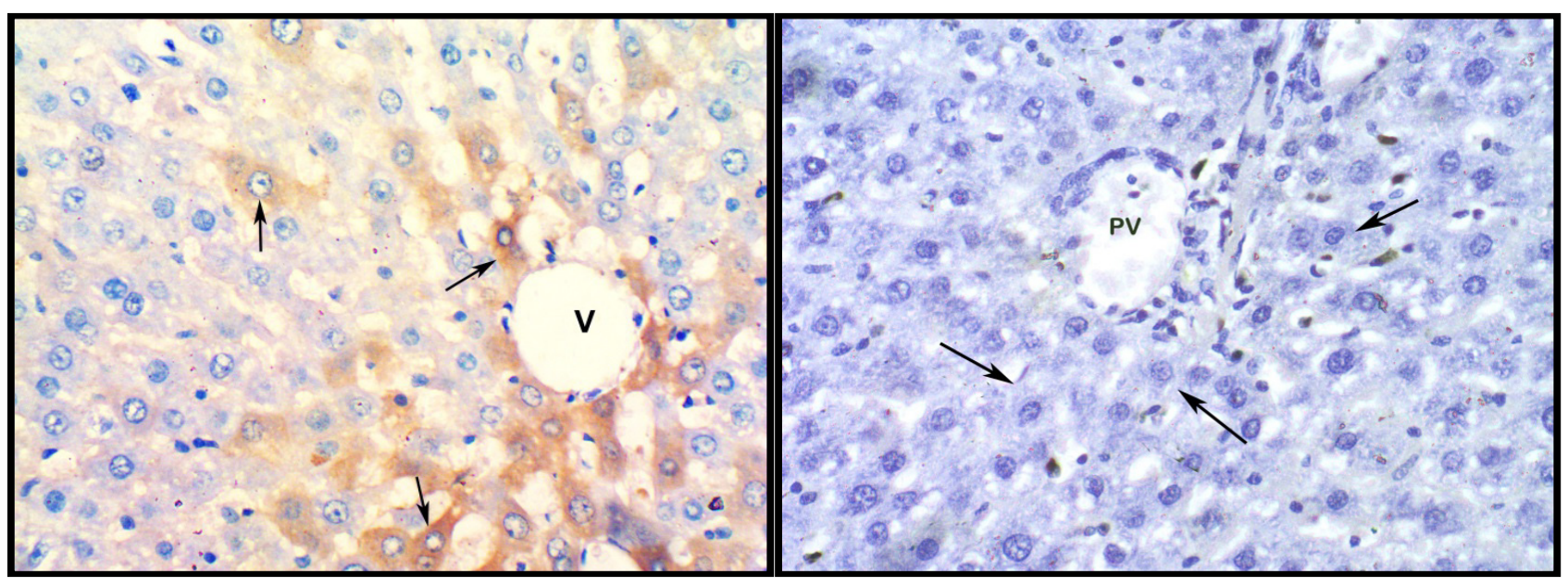

Fig. 22: A photomicrograph of a section in rat liver of group five(A) revealing VEGF positively immunostained hepatocytes (black arrows) mostly around the central vein (V). (B) revealing all hepatocytes around the portal tract, with negative VEGF immunostaining (black arrows). (VEGF immunoreactivity. X400)

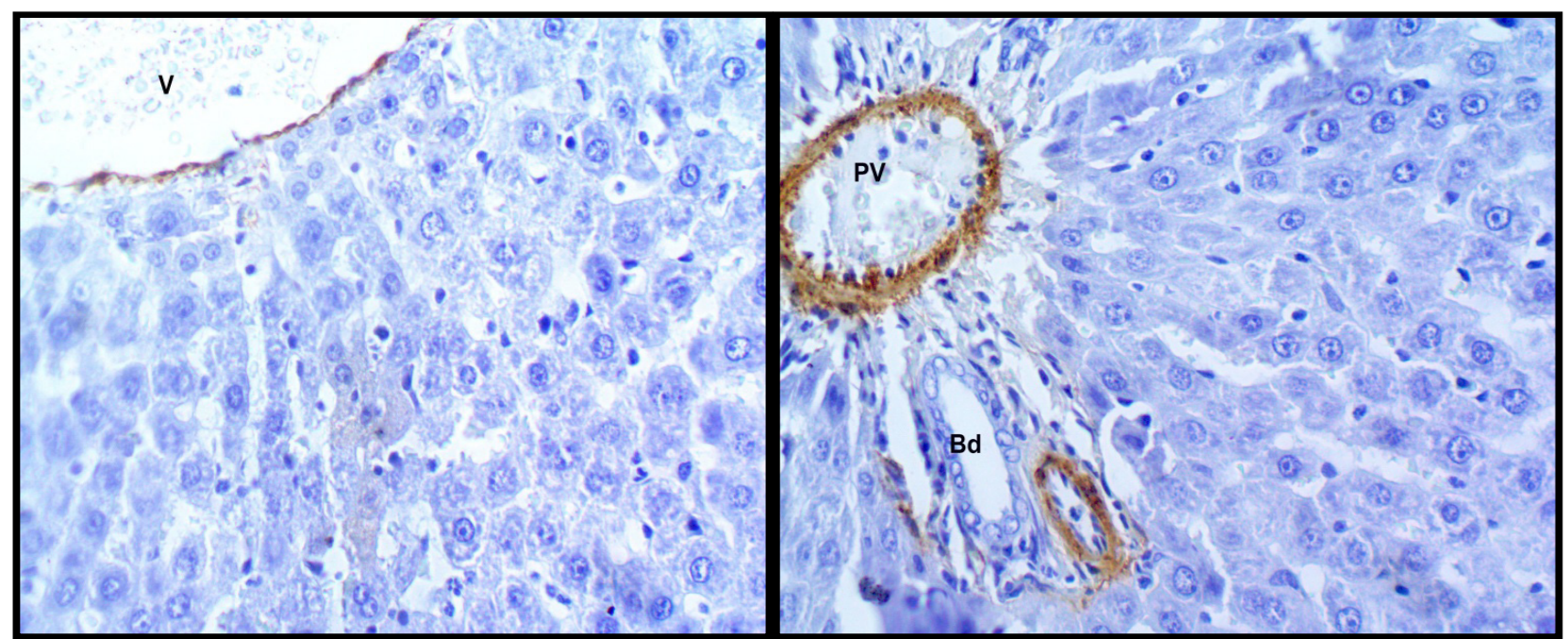

Fig. 23: A photomicrograph of a section in rat liver of control group (A)showing only cytoplasmic immunostaining in the cytoplasm of smooth muscle of the wall of the central veins (V).(B) showing only cytoplasmic immunostaining in the cytoplasm of the smooth muscle of the vessel wall in the portal area. $(\alpha$-SMA immunoreactivity. X400) 


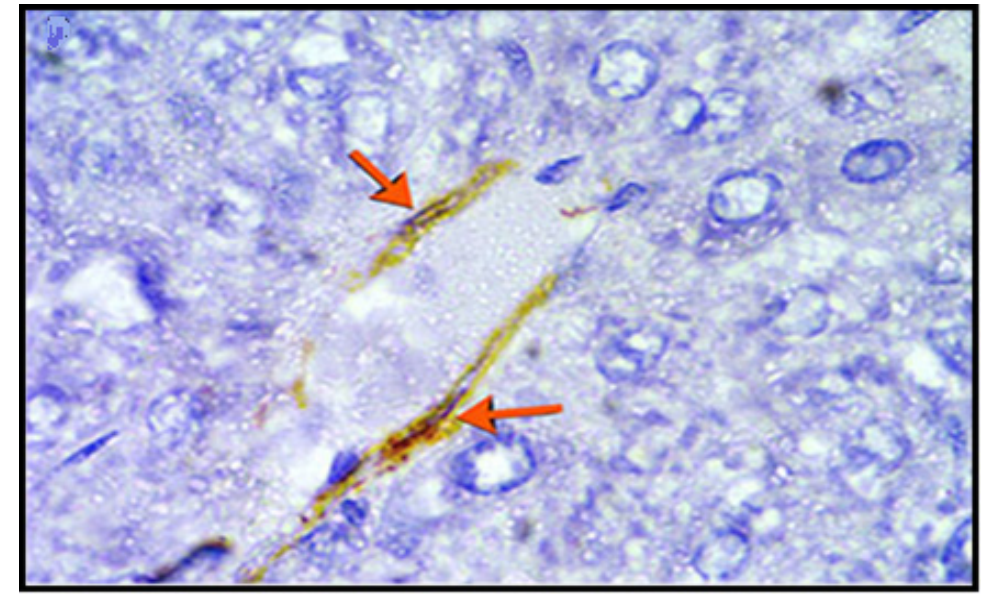

Fig. 24: photomicrographs of a section in rat liver of group two showing spindle shaped cells with positive cytoplasmic immunostaining for $\alpha$-SMA (red arrows) in the wall of blood sinusoids. $\alpha$-SMA immunoreactivity X1000

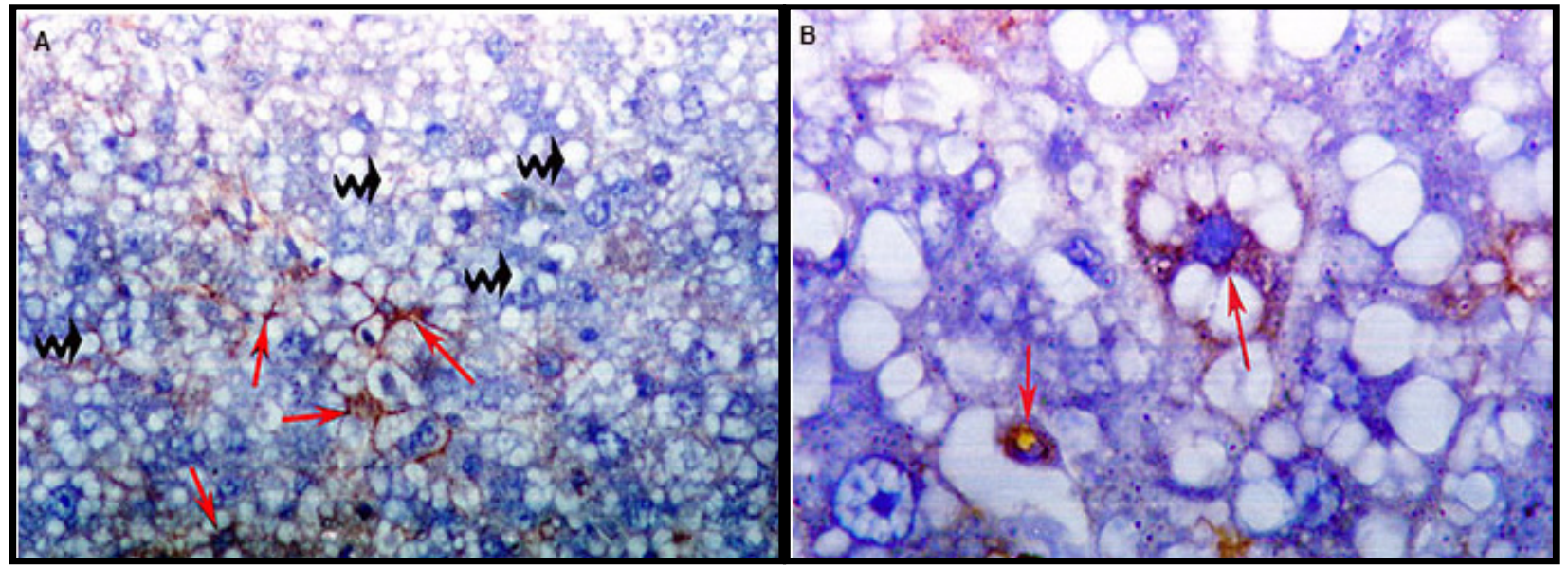

Fig. 25: Photomicrographs of a section in rat liver of group two showing branched cells (red arrows) with positive cytoplasmic immunoreaction for $\alpha$-SMA scattered among the vacuolated hepatocytes (zigzag arrows).
A: $\alpha$-SMA immunoreactivity X400
B: $\alpha$-SMA immunoreactivity X1000

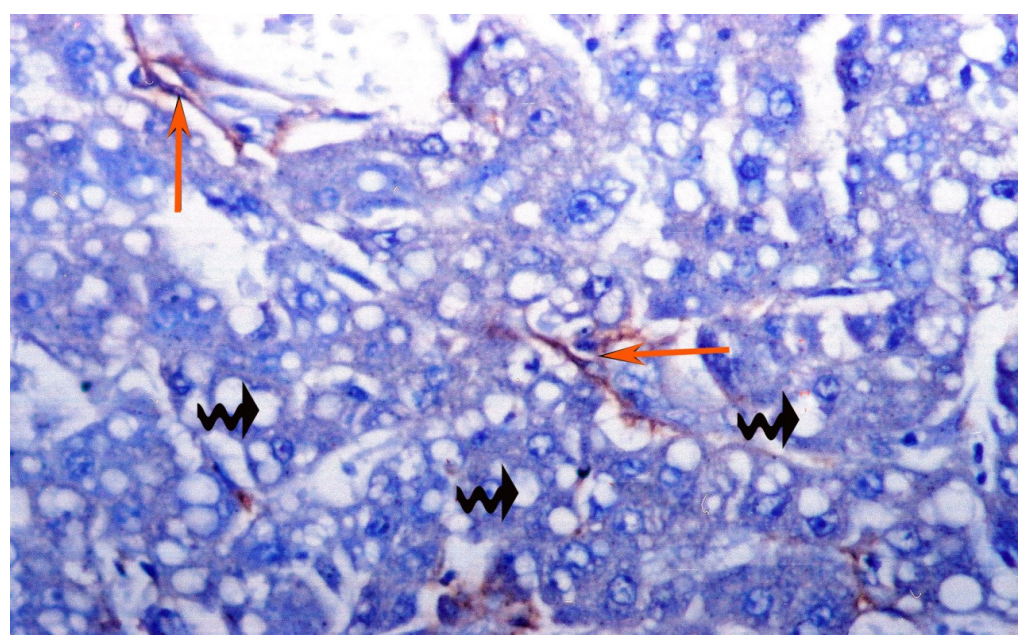

Fig. 26: A photomicrograph of a section in rat liver of group two showing $\alpha$-SMA positive flat cells (red arrows) among the vacuolated hepatocytes (zigzag arrows). ( $\alpha$-SMA immunoreactivity. X400) 


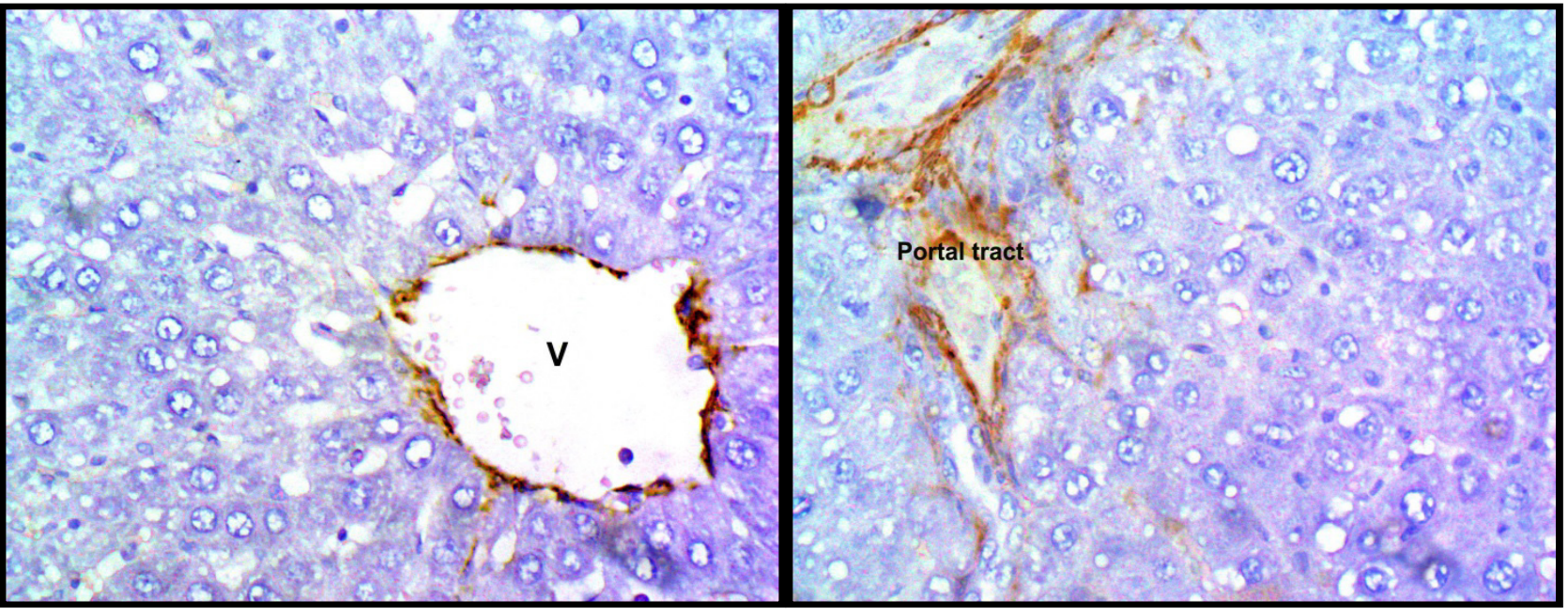

Fig. 27: A photomicrograph of a section in rat liver of group three(A) showing only cytoplasmic immunoreaction in the cytoplasm of smooth muscle of the central vein (V). (B) showing only cytoplasmic immunoreaction in the smooth muscle of the vessel wall in the portal tract. ( $\alpha$-SMA immunoreactivity. X400)

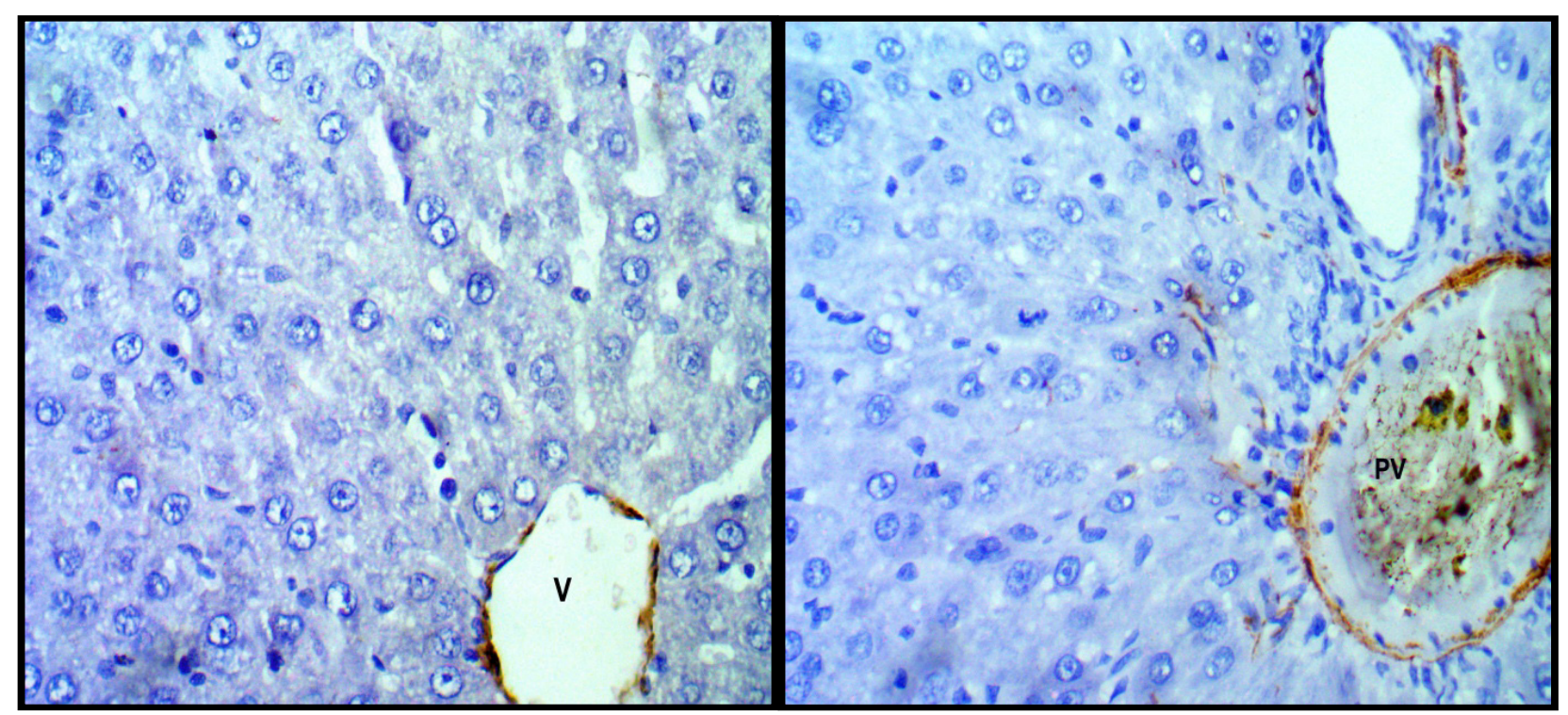

Fig. 28: A photomicrograph of a section in rat liver of group four(A) showing only cytoplasmic immunoreaction in the smooth muscles of the wall of the central vein (V).(B) showing only cytoplasmic immunoreaction in the smooth muscles of the vessel walls in the portal area. ( $\alpha$-SMA immunoreactivity. X400)

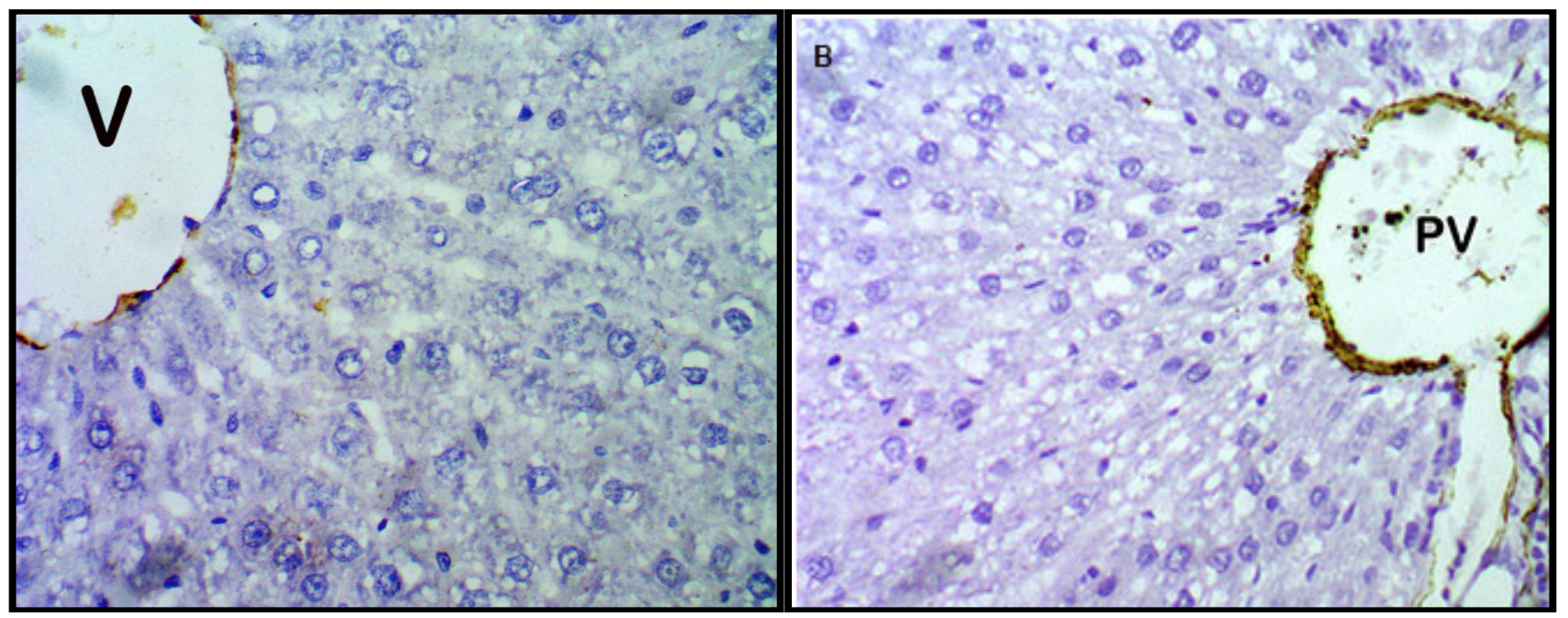

Fig. 29: A photomicrograph of a section in rat liver of group five(A) revealing cytoplasmic immunoreaction for $\alpha$-SMA in the wall of the central vein (V).(B) revealing positive cytoplasmic immunoreaction of smooth muscles of the vessel wall in the portal tract. ( $\alpha$-SMA immunoreactivity. X400) 
Table 1: The mean $\pm \mathrm{SD}$ of the LW/BWR of the different groups (\%) and their relation to the control

\begin{tabular}{lcc}
\hline Group & Mean LW/BWR (\%) & SD \\
\hline Group I (control) & 4.51 & 0.05 \\
Group II (D3) & $2.16^{\boldsymbol{\bullet}}$ & 0.12 \\
Group III (D7) & $3.28^{\mathbf{*}}$ & 0.26 \\
Group IV (D14) & $4.16^{\mathbf{\bullet}}$ & 0.20 \\
Group V (D21) & $4.74^{\mathbf{}}$ & 0.34 \\
\hline
\end{tabular}

Where $\mathrm{D}=$ day, $\mathrm{SD}=$ standard deviation.

- = significant when compared to control

$\boldsymbol{\nabla}=$ significant when comparing each group with previous one

Table 2: The mean $\pm \mathrm{SD}$ of the area $\%$ of PCNA positive reaction of the different groups and their relation to the control

\begin{tabular}{lcc}
\hline Group & Mean LW/BWR (\%) & SD \\
\hline Group I (control) & 3.95 & 1.02 \\
Group II (D3) & $18.06^{\bullet}$ & 2.01 \\
Group III (D7) & $8.89^{\mathbf{v}}$ & 1.43 \\
Group IV (D14) & 3.92 & 1.04 \\
Group V (D21) & 3.99 & 1.04 \\
\hline
\end{tabular}

Where $\mathrm{D}=$ day, $\mathrm{SD}=$ standard deviation.

- = significant when compared to control

$\boldsymbol{\nabla}=$ significant when comparing each group with previous one

Table 3: The mean \pm SD of the area $\%$ of VEGF positive reaction of the different groups and their relation to the control

\begin{tabular}{lcc}
\hline Group & Mean LW/BWR (\%) & SD \\
\hline Group I (control) & 2.55 & 0.96 \\
Group II (D3) & $68.21^{-}$ & 5.07 \\
Group III (D7) & $35.05^{\mathbf{v} \cdot}$ & 4.81 \\
Group IV (D14) & 2.47 & 0.96 \\
Group V (D21) & 2.48 & 0.88 \\
\hline
\end{tabular}

Where $\mathrm{D}=$ day, $\mathrm{SD}=$ standard deviation.

- = significant when compared to control

$\boldsymbol{\nabla}=$ significant when comparing each group with previous one

Table 4: The mean \pm SD of the area $\%$ of $\alpha$-SMA positive reaction of the different groups and their relation to the control

\begin{tabular}{lcc}
\hline Group & Mean LW/BWR (\%) & SD \\
\hline Group I (control) & 3.24 & 1.41 \\
Group II (D3) & $12.36^{-}$ & 3.85 \\
Group III (D7) & 3.17 & 1.48 \\
Group IV (D14) & 2.86 & 1.12 \\
Group V (D21) & 2.96 & 1.47 \\
\hline
\end{tabular}

Where $\mathrm{D}=$ day, $\mathrm{SD}=$ standard deviation.

- = significant when compared to control

$\boldsymbol{\nabla}=$ significant when comparing each group with previous one

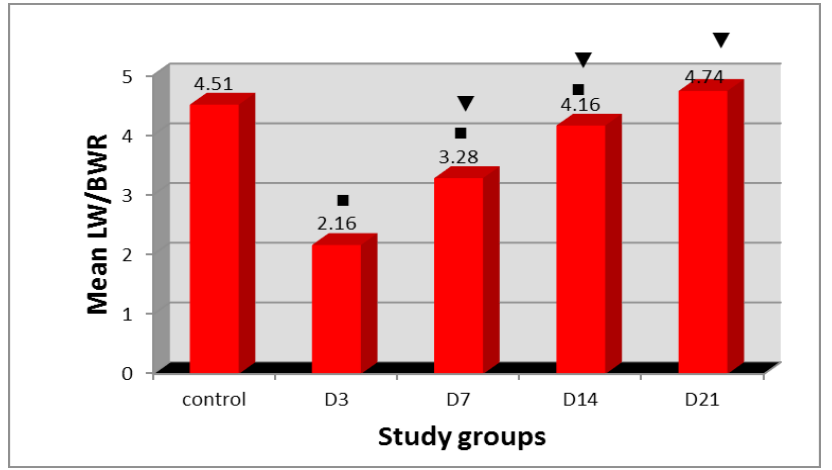

Histogram 1: Showing the mean liver weight /body weight ratio of the different groups (\%) in comparison to the control group.

- = significant when compared to control

$\boldsymbol{\nabla}=$ significant when comparing each group with previous one

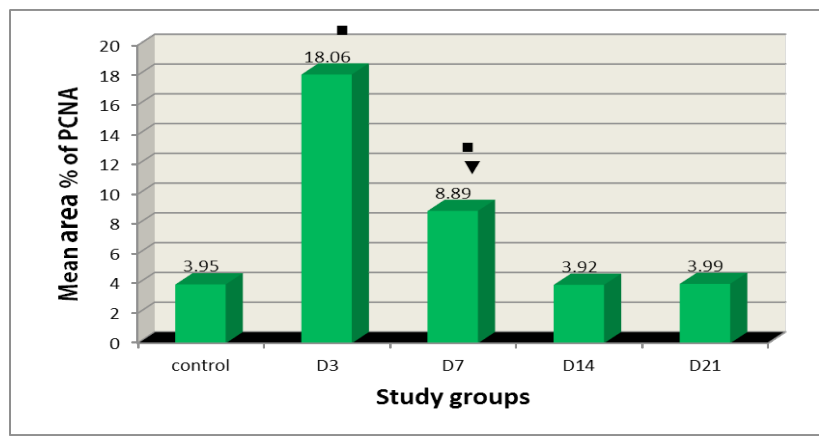

Histogram 2: Showing the mean area \% of PCNA of the different groups in comparison to the control group.

- = significant when compared to control.

$\boldsymbol{\nabla}=$ significant when compared to group II.

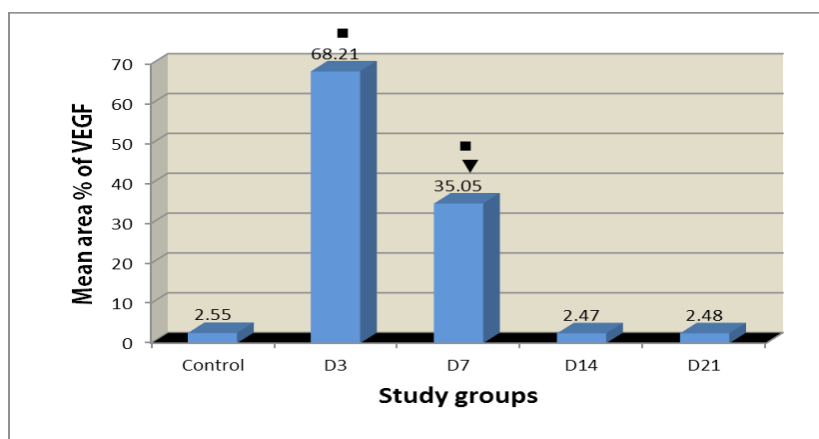

Histogram 3: Showing the mean area \% of VEGF of the different groups in comparison to the control group.

- = significant when compared to control.

$\boldsymbol{\nabla}=$ significant when compared to group II. 


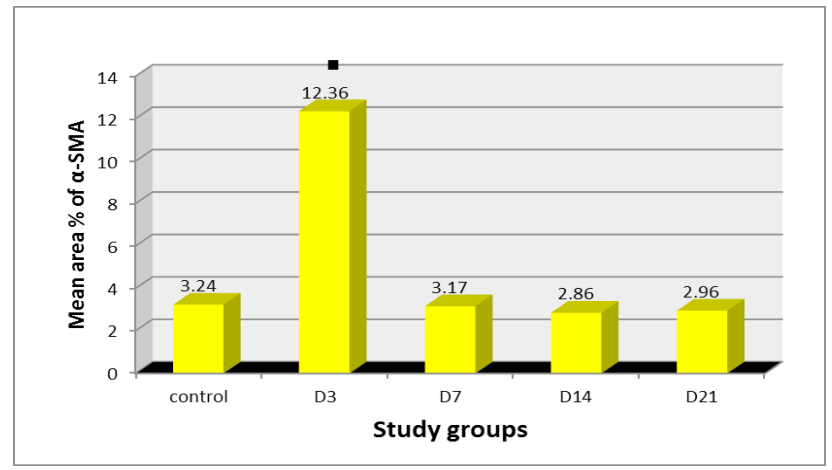

Histogram 4: Showing the mean area $\%$ of $\alpha$-SMA of the different groups in comparison to the control group.

- significant when compared to control.

\section{DISCUSSION}

Hepatocellular carcinoma ranks the fifth in frequency, among all malignancies, all over the world. It is the third most common cause of cancer mortality, with about 500,000 cancer related deaths annually. Hepatocellar carcinoma is resistant to both cytotoxic chemotherapy and radiotherapy, leaving surgery the main therapeutic approach ${ }^{[20]}$. Most hepatectomies are performed for the treatment of hepatic neoplasms, both benign or malignant. Benign neoplasms include hepatocellular adenoma, hepatic hemangioma and focal nodular hyperplasia. The most common malignant neoplasms of the liver are metastases; those arising from colorectal cancer are among the most common, and the most amenable to surgical resection. The primary malignant tumour of the liver is the hepatocellular carcinoma. Hepatectomy may also be the procedure of choice to treat intrahepatic gallstones or parasitic cysts of the liver. Partial hepatectomies are also performed to remove a portion of a liver from a live donor for transplantation ${ }^{[1]}$.

The objective of this study was to establish an animal model of liver regeneration after partial hepatectomy to investigate the regenerative phenomenon at different time intervals and to elucidate the role of hepatic stellate cells (HSCs) and angiogenesis in this type of liver regeneration after PH. In the current study, liver regeneration was induced by surgical resection of about $70 \%$ of the liver parenchyma according to the technique first described ${ }^{[14]}$.

The choice of partial hepatectomy as a model for liver regeneration depended on many aspects. The removal of the resected tissue was not associated with massive necrosis or inflammation, when compared to the acute inflammation and necrosis produced by other methods that use hepatic toxins such as carbon tetrachloride. The operation could be also, performed in a few minutes with immediate initiation of the regenerative response so; it can be well timed from a specific starting point. Subsequently, precise and accurate calculation and evaluation of the regenerative process can be obtained ${ }^{[9 a n d 21]}$.

The $70 \%$ partial hepatectomy is the most often used model because it is simple, easy, reproducible and well tolerated by the rats without postoperative mortality ${ }^{[22]}$. In addition, regeneration of liver tissue has a threshold of $30 \%$ partial hepatectomy $(\mathrm{PH})$, below which, liver regeneration slows down ${ }^{[23]}$, whereas an $80 \% \mathrm{PH}$ leads to failure of liver regeneration and a high mortality rate ${ }^{[24]}$.

As regard to the gross results observed in the present work, marked pallor of the liver tissue was observed in group II and not in the other groups. Mild adhesions of the liver to the diagram and adjacent abdominal organs were also, noted in the same group. Extensive adhesions were observed in group III and IV which decreased in group V to become minimal. In addition, yellowish discoloration at the resected stump was seen in all groups. These findings were consistent with those obtained by some researchers ${ }^{[2]}$ who reported similar results after PH in dogs, in addition to the fatty degeneration seen at the surgical stump as a complication of the operation. Previous study also, reported pallor of the liver tissue and its adhesion to the peritoneal cavity after $\mathrm{PH}$ in rats ${ }^{[26]}$.

At day three, there was a significant decrease $(P<0.05)$ in the mean liver weight to body weight ratio (LW/BWR) when compared to the control group. At days 7, 14 and 21 , there was gradual significant increase $(P<0.05)$ in the mean LW/BWR that reached the control level only at day 21 with no significant difference $(P>0.05)$ as compared to control. This could indicate proliferation and regeneration of the remaining two liver lobes so that, the LW/BWR was restored and reached the control number 21days postoperatively. This was in agreement with some authors who found that reconstitution of the liver mass took place 2-3 weeks after $\mathrm{PH}$ in rats ${ }^{[27]}$.

However, other investigators reported that the restoration of the original liver mass took place at different time intervals after PH. In addition, reported an increase in the LW/BWR that reached the control value 7days after $70 \% \mathrm{PH}$ in mice ${ }^{[28]}$. They showed that the majority of the liver weight occurred by postoperative day 4 and the entire mass of the original liver was reconstituted by postoperative day 8 following 2/3 PH in mice. Other researcher detected an increase in the LW/BWR $12 \mathrm{hr}$ after $\mathrm{PH}$ in mice and most of liver mass was restored by day $7^{[29]}$. Moreover, an increase in the LW/BWR after 70\% $\mathrm{PH}$ in rats, which had returned to the preoperative levels by 14 days ${ }^{[30]}$.

Many explanations were mentioned as reasons for the increase in the weight of the liver. In addition to the regeneration of hepatocytes, many authors attributed the increase in liver weight to other factors. Previous study proved that this increase was due to the lymphocyte generation in the liver itself during the early phase of liver regeneration (12 hours postoperative) ${ }^{[31]}$. Some authors rationalized the increase in liver weight to the increase in the portal inflow. They declared that proper portal supply of either venous or arterial source could initiate and maintain liver regeneration ${ }^{[32]}$. This was evident in this work where congestion of the blood sinusoids, portal vein branches and central veins were clearly observed in the studied 
groups. It was explained that the increase in liver weight was due to hepatocyte hypertrophy caused by partial lipid and glycogen accumulation within hepatocyte cytoplasm. However, the lipid and glycogen amount returned to normal levels by the completion of liver regeneration ${ }^{[33]}$. This could be confirmed in the current study where vacuolation of the hepatocyte cytoplasm was early observed in group II.

Some researchers demonstrated that the restoration of the lost liver mass was correlated with the number of proliferating hepatocytes. They suggested that the gain of liver weight depended principally on hepatocyte proliferation which constituted a fundamental cellular mechanism responsible for hepatic regeneration after $\mathrm{PH}^{[29]}$. However, it was reported that the increase in hepatocyte number alone, could not account for the increase in the liver weight. Moreover, a combination of an increase in hepatocyte size and number could account for the increase in liver weight after $70 \% \mathrm{PH}^{[34]}$.

Regarding the $\mathrm{H}$ and $\mathrm{E}$ results in the present study, in group II (three days postoperative), vacuolation of the hepatocyte cytoplasm was observed and not in the remaining groups. This was in accordance with some authors who reported vaculation within the hepatocyte cytoplasm 8 weeks after $\mathrm{PH}$ in dogs, and observed macrovesicular steatosis early after PH in mice ${ }^{[25 a n d 35]}$. These vaculations, together with the grossly apparent liver pallor in this group could indicate fatty accumulations which physiologically occur in early regeneration following $\mathrm{PH}$ in rodents. Previous study reported that transient fatty liver occurs $24 \mathrm{~h}$ to $72 \mathrm{~h}$ after $\mathrm{PH}$ in rats and disappears spontaneously ${ }^{[21 \text { and36] }}$. This was thought to represent a metabolic adaptation of hepatocytes, so that the emerging new ones would have readily available energy and material they could use to build cellular membranes. They added that the regenerative process is greatly dependent on caveolin protein which is concerned with the physiological accumulation of fat.

However, some authors attributed these vacuolations to ultrastructural alterations of the cytoplasmic organelles of hepatocytes accompanied by decreased glycogen and increased lipid content in the cytoplasm ${ }^{[37]}$. Other study explained the vaculations seen within the hepatocytes cytoplasm 8 weeks after $\mathrm{PH}$ in dogs, by vacuolar degeneration caused by the hypoxia resulting from the regenerated hepatocytes that need more oxygen and nutrition than the available amount ${ }^{[25]}$. Moreover, previous researchers observed macrovesicular steatosis early after $\mathrm{PH}$ in mice and explained it by failure of the enzyme system to metabolize lipids ${ }^{[38]}$.

Hepatocyte swelling was noted in groups II and III; while apparently normal hepatocytes were seen in the remaining two groups. These findings agreed with some authors who observed similar results ${ }^{[35]}$. Hypertrophy of hepatocytes may be a major component of the regenerative process, which may precede or coincide with hepatocyte proliferation. Hepatocytes hypertrophy was predominant after $30 \% \mathrm{PH}$, however a combination of both hypertrophy and hyperplasia was present after $70 \% \mathrm{PH}^{[34]}$.
Moreover, loss of the neatly arranged hepatocytes was noted three days postoperatively (group II), which appeared to be more regularly arranged in the following groups. This was similar to previous authors who noted disturbed hepatocyte arrangement and clustering. This could indicate remodeling of the hepatic lobular architecture, which was temporarily distorted by the regenerative response ${ }^{[38]}$.

In the present work, HandE stained sections revealed rapid activity of mitosis detected mostly on third postoperative day. Different hepatocytes were seen in different stages of mitosis which were randomly distributed in the liver lobules with no specific localization. These mitotic figures could explain the early onset of liver regeneration immediately after $\mathrm{PH}$. The early onset of liver cell proliferation after partial hepatectomy was documented by other investigators ${ }^{[39]}$ reported a peak of the proliferative index 12-36h after PH up to 48 hours postoperatively. Some researchers stated that after $70 \% \mathrm{PH}$, the hepatocytes tended to proliferate in the periportal regions and the peak of mitosis was reached 36 hours postoperatively ${ }^{[40]}$.

In the present study, multiple hepatocytes with pale cytoplasm were observed on third day after PH. This finding was consistent with other studies which reported avascular hepatocyte clusters. Some authors confirmed the presence of nonvascular hepatocyte clusters at day three and seven, while others reported these finding at day two and three after PH. They explained their formation by the early onset of hepatocyte proliferation after $\mathrm{PH}$ and later on proliferation of nonparenchymal cells (NPCs) which was delayed for 24 hour after hepatocyte proliferation. This chronological order of cell proliferation resulted in the formation of avascular hepatocyte islands throughout the liver lobule ${ }^{[38 a n d 41]}$.

Dilatation and congestion of the portal vein branches and blood sinusoids were observed in group II while, dilation of the central vein and blood sinusoids was observed in group III. The central vein, blood sinusoids and portal vein branche of group IV were dilated and congested. This could be explained by the relatively more blood volume reaching the remaining two lobes after the operation. In group $\mathrm{V}$, the dilation and congestion were limited to the blood sinusoids alone which may be a compensatory mechanism to accommodate the more incoming blood, throughout life after $\mathrm{PH}$, to minimize the central and portal venous pressure. Previous researchers stated hemodynamic changes following $2 / 3 \mathrm{PH}$ in rats. They postulated a threefold increase in the portal vein blood going to the residual lobes following the operation. After $2 / 3 \mathrm{PH}$, the entire portal circulation continues to traverse through a liver reduced to $1 / 3$ of its original size so, the portal blood flow per hepatocyte or unit liver mass increased 3 folds after $2 / 3 \mathrm{PH}^{[9]}$.

In group II, the blood sinusoids are numerous, distorted, wider and shorter with interrupted course when compared to control group which appear straight and relatively maintain constant sinusoidal width along its course. This 
could point to the formation of new blood vessels which is interrupted by the proliferating islands of hepatocytes. Previous authors demonstrated that sinusoidal dilatation, loosening of endothelial cells and increased porosity were the first steps in angiogenesis and new vessel formation ${ }^{[42]}$. This was evident in the current result which showed marked sinusoidal dilatation in groups II, III and detached endothelial cells in group III only. In addition, the fatty accumulation reported in group II could be considered as a land mark for increased porosity and fenestration diameter which allowed greater access for chylomicrons into space of Disse and hepatocytes ${ }^{[43]}$.

Regarding nonparenchymal cells, the present study revealed wide distribution of von Kupffer cells (KCs) in the sinusoidal wall, mainly in groups II and III. In addition, they had heterogenous cytoplasm and nuclei with variable degrees of chromatin condensation denoting activity of Kupffer cells. This finding may go parallel with the increased proliferation of hepatocytes. This could point to the integrative role of KCs and hepatocytes and to the enhancing effect of $\mathrm{KCs}$ on liver regeneration after $\mathrm{PH}$. Previous studies showed an inhibitory effect of KCs on the regenerative process, after $\mathrm{PH}$. An inhibitory effect of $\mathrm{KCs}$, as their selective depletion resulted in enhanced liver regeneration ${ }^{[44]}$

A stimulatory role of $\mathrm{KCs}$ on hepatic regeneration after $\mathrm{PH}$ by enhancing the expression of TNF- $\alpha$, IL- 6 and HGF. Moreover, KCs had a stimulatory effect on liver regeneration, greatly dependant on macrophage colony stimulating factor (M-CSF) whose deficiency resulted in marked reduction in the number of $\mathrm{KCs}$ and inhibition of hepatocyte proliferation ${ }^{[45 a n d 46]}$. Previous authors elucidated the role of KCs in liver regeneration. They demonstrated that KCs are a major source of both pro-proliferative andanti-proliferative mediators that could be encountered in both stimulatory and inhibitory effects during regeneration. They attributed the discrepancy in the previous results to the difference of the time factor. Kupffer cell depletion whether, before or after PH could affect the regenerative process. The activity of KCs during early regeneration was marked in the early priming phase, but decreased after seven days postoperatively, in the late termination phase $^{[47 \text { and } 48]}$.

Enlargement of the sinusoidal endothelial cells was reported in groups II and III. Few endothelial cells were seen detached in group III which may be attributed to the haemdynamic changes and sinusoidal shear stress caused by the increased portal flow after PH. These findings run parallel with those of some authors who proved activation of hepatic SECs early after PH due to the higher sensitivity of SECs to the increased portal flow. They clarified their vital role in supplying nutrients and growth factors to the proliferating hepatocytes through the formation of new vessels during regeneration ${ }^{[49]}$. Endothelial cell enlargement may be associated with the hepatocyte hypertrophy and the wide distribution of Kupffer cells, observed in the same two groups, as a component of the regenerative phenomenon. Both hepatocytes and nonparencymal cells are quiescent under normal conditions but were activated and proliferated up to 5 days after $\mathrm{PH}^{[50]}$.

In only groups II and III, the portal area showed more branching of the bile ducts with apparently increased size and number of their epithelial lining, which could indicate a regenerative process within the biliary system. This regenerative process goes hand in hand with hepatocyte proliferation and could form an accessible drainage pathway for the bile secreted by the proliferating hepatocyte. Similar histological changes in the portal areas after $\mathrm{PH}$ in dogs have been reported ${ }^{[25]}$. Proliferation of the bile ducts could also, be controlled by oval cells ${ }^{[51]}$.

In the current study, mononuclear cellular infiltrations around the portal area as well, scattered among the hepatocytes cords were reported in group V. These cellular infiltrations were observed late, 21 days postoperatively and not seen in the previous groups. They could be engaged or encountered in the termination process of liver regeneration as they might secrete certain mediators and cytokines that prevent the overshooting of the regenerative process impeding the formation of liver cancers. Working in mice, mononuclear cellular infiltrations, 4-12hrs, after PH up to the 7th day, the same day when the LW/BWR was restored $^{[31]}$. Moreover, inflammatory cell infiltrates early after $\mathrm{PH}$ during the first 3 days postoperative ${ }^{[24]}$

Regarding the PCNA immunohistochemical results in the present work, the control sections revealed very few hepatocytes with positive immunoreaction. This result was consistent with previous authors who mentioned that approximately, one hepatocyte in $20,000(0.005 \%)$ is in the mitotic phase of the cell cycle and the rest are quiescent ${ }^{[52]}$.

Moreover, the current study revealed a significant increase $(p<0.05)$ in the mean area $\%$ of PCNA positive reaction in groups II and group III, when compared to the control although, this increase was significantly lower $(p<0.05)$ in group III when compared to group II. In groups IV and V, no significant difference $(p>0.05)$ was noted when compared to the control. The PCNA results indicated early hepatocyte proliferation occurred as early as the first three days after PH which could be correlated with the mitotic figures detected in HandE stained sections in this group. This rate of hepatocyte proliferation decreased gradually to reach the normal proliferating rate around day fourteen.

These results were in accordance with those of some authors who studied hepatocyte proliferation at different time intervals after $\mathrm{PH}$ in rats ${ }^{[38]}$. They found an increase in the hepatocyte proliferation, as shown by the hepatocyte proliferation marker (Ki67) expression, 2 days after $\mathrm{PH}$ and up to the fourth day. Moreover, An increase in the PCNA expressing hepatocytes $24 \mathrm{hr}$ after $\mathrm{PH}$ in rats and decreased 5 days postoperativelyand high proliferation of hepatocytes, denoted by Ki 67 positive immunreaction, on day 2 and 4 after $70 \% \mathrm{PH}$ in rats have been reported ${ }^{[15 a n d 53]}$. Similarly, some researchers reported increased PCNA 
expression in hepatocyte nuclei 3 day after $\mathrm{PH}$ in rats and decreased at day $7^{[10]}$.

In the present study, proliferating cells after $\mathrm{PH}$ were observed in both periportal and pericentral regions at day 3 postoperatively. This observation could be explained that initial hepatocyte proliferation started about 24 hour after resection in the periportal areas and then involved both periportal and pericentral areas by $36-48$ hours, with completion of the hepatocytes replication after 72 hours $^{[21]}$. The periportal hepatocytes differed from those in the pericentral area in that they had different functional capacities caused by the higher concentrations of incoming oxygen, hormones and gut derived hepatotrophic factors which resulted in zonal distribution of hepatocytes proliferation ${ }^{[54 a n d 55]}$. Moreover, the existence of ultrastructural difference between periportal hepatocytes and pericentral ones, which led to an increase in the reactive oxygen species (ROS) production after $\mathrm{PH}$, due to mitochondrial alterations. The increased ROS played a significant role in the modulation of hepatocyte proliferation so, cell proliferation initiated in the periportal zone, and then proceeded into the pericentral vein region ${ }^{[56]}$.

The distribution of the positive VEGF immunostained hepatocytes, in the present study, suggests that VEGF is normally secreted by the pericentral hepatocytes which suffer from lack of $\mathrm{O} 2$ and nutrition. After partial hepatectomy, the mean area percent of VEGF immunostaining showed a significant increase in groups II and III when compared to control. The VEGF immunoreaction was diffuse in group II, including all hepatocytes around central vein and those around the portal tracts while limited to midzonal and pericentral hepatocytes in group III. This may be consistent with the appearance of dilated, congested blood sinusoids in HandE in group II. The current results could point to the role of hepatocytes in secretion of VEGF early after PH. VEGF may aggravate new blood vessels growth to supply the rapidly growing masses of hepatocytes with nutrition and oxygen. In the last two groups, IV and V, all hepatocytes showed negative VEGF immunoraction with no significant difference $(p>0.05)$ when compared to the control. This could indicate that the requirements of liver regeneration, including hepatocyte proliferation as well as angiogenesis were completed by the first postoperative week and only remodeling of the extracellular matrix with redistribution of hepatocytes and restoration of the lobular structure of the liver occurred during the second two weeks.

These results were consistent with that obtained by some authors who reported positive cytoplasmic immunostaining, in control rats, limited to the pericentral hepatocytes around central vein ${ }^{[57]}$. In addition,some others reported that VEGF expression in periportal hepatocytes and reached a maximal level in both periportal and pericentral areas 48-72 hours after PH. They also, found marked increase in the expression of VEGF mRNA between 48 and 90 hours after $70 \% \mathrm{PH}$ in rats, and decreased gradually in the following hours ${ }^{[58]}$. Morover, an increase in the hepatocyte expression of VEGF between days 3 and 4 that dropped at day 7, reaching almost the preoperative levels at day 14 postoperatively ${ }^{[38]}$.

However, previous authors showed that VEGF expression started to increase, as early as 26 hour after $\mathrm{PH}$ with a peak at 28 hour. Furthermore, the hepatocyte proliferation showed an increase $50 \mathrm{~h}$ after operation. They concluded that the VEGF release by hepatocytes preceded the hepatocytes proliferation during liver regeneration after $\mathrm{PH}$ in mice, which was inconsistent with the current results ${ }^{[59]}$.

Some researchers declared a complex paracrine interaction between hepatocytes and endothelial cells present during liver regeneration. Hepatocytes do not typically express VEGF receptors, although exogenously added VEGF has been shown to increase hepatocyte proliferation, suggesting a paracrine effect operating through the endothelial cells ${ }^{[28]}$. While others demonstrated that the importance of VEGF during liver regeneration was mediated through its receptor VEGFR1 and VEGFR2. VEGF binds to its receptors with subsequent proliferation of the endothelial cells which release growth factors such as IL-6 and hepatocyte growth factor (HGF) triggering angiogenesis and liver regeneration. Furthermore, blockage of VEGFR2 by intraperitoneal injections of anti-VEGFR-2 antibodies led to impairment of liver regeneration ${ }^{[60]}$.

The present study showed that VEGF expression in the regenerating liver reached peak at day 3 postoperatively and decreased gradually at day 7 , which coincided with hepatocyte proliferation, as assessed by PCNA immunostaining. The parallel course of both PCNA and VEGF during this study could be explained by the importance of VEGF for early liver regeneration after PH. It seems to be a viscous circle as the proliferating hepatocytes secrete VEGF which stimulates further hepatocyte proliferation.

As regard to the $\alpha$-SMA, the control liver showed only positive cytoplasmic immunreaction in the cytoplasm of the smooth muscle of the vessels wall in the portal areas and central veins. A significant increase $(p<0.05)$ in the mean area $\%$ of $\alpha$-SMA positive immunoreactivity was reported on the third day (group II) postoperative while, no significant difference $(p>0.05)$ was noted in groups III, IV and $\mathrm{V}$ as compared to the control group.

In group II, in addition to the positive immunreaction in the vessels wall, the results showed flat branched cells with $\alpha$-SMA positive immunreaction, in blood sinusoids and in between hepatocytes, denoting activated hepatic stellate cells. The presence of activated HSCs in between hepatocytes and their timing of activation which coincided with the appearance of hepatocytes clusters in HandE sections could indicate hepatocyte interaction with HSCs affecting each other. In addition, the presence of HSCs in blood sinusoids may indicate their role in remodeling of the blood sinusoids and restoration of normal liver sinusoidal structure. Parallel to the current results, some authors demonstrated that the sinusoidal localization of HSCs 
with their long cytoplasmic processes promoted them to interact with adjacent cell types. They have direct contact with endothelial cells and interact with hepatocytes via microspines projecting from the cytoplasmic processes ${ }^{[61]}$.

In the current work, activation of HSCs in group II was associated with marked expression of VEGF in the same group, and the significant decrease in the VEGF expression in group III was associated with inactivation of HSCs as denoted by $\alpha$-SMA immunostaining. This chronological course could indicate interdependence between the activation of HSCs and VEGF expression. The release of several mediators, by HSCs, as TGF- $\beta 1$ and PDGF, were known to have potent proliferative and angiogenic properties which increased the VEGF expression ${ }^{[28]}$.

The finding of this study concerning $\alpha$-SMA results were consistent with that of previous researchers who reported a clear increase in $\alpha$-SMA expressing HSCs on day 1 , after $70 \% \mathrm{PH}$ in rats, which peaked on day 3 and declined again by day $7^{[38 a n d 41]}$. Some authors detected $\alpha$-SMA expressing HSCs which were maximal at day 3 after $\mathrm{PH}$ and decreased at day $14^{[62]}$.

The results of negative immunohistochemical expression of $\alpha$-SMA in group III were inconsistent with those of previous authors who detected positive immunohistochemical expression. This discrepancy may be attributed to little expression of $\alpha$-SMA in the HSCs 7 days after PH that could not be detected by immunohistochemical techniques and further sensitive methods may be needed for detection ${ }^{[62]}$.

In transgenic mice models, the finely tuned HSCs response is an important factor to ensure adequate liver regeneration as deficiently or uncontrolled activation of HSCs could translate into regenerative defects ${ }^{[63]}$. In mice with genetically lacking HSC functions, an insufficient HSCs activation with an abnormal liver repair ${ }^{[64]}$. On the other hand, in mice with genetic mutation in the $\alpha 1$ (I) chain of type I collagen, persistent HSCs activation, progressive liver fibrosis, in addition to failure of proper liver regeneration after $\mathrm{CCl} 4$ injury ${ }^{[65]}$.

The role of HSCs in hepatocyte proliferation in primary culture models. They showed that HSCs might stimulate the hepatocyte proliferation through the generation of hepatocyte growth factor (HGF), Heparan sulphate (HS) and Heparan sulphate proteoglycans (HSPG) ${ }^{[66]}$.

In more recent studies, the proliferative effects of HSCs on hepatocytes were confirmed by previous authors who found severe liver damage and decreased survival rate of the animals due to depletion of activated HSCs with gliotoxin. In addition, they reported a threefold increase in hepatocyte apoptosis and a $66 \%$ decrease in the number of proliferating ones. They added that depletion of activated HSCs inhibited oval cell reaction ${ }^{[67]}$.

Collectively, regarding the role of nonparenchymal cells in liver regeneration, the results showed that Kupffer cells were widely distributed three and seven days after $\mathrm{PH}$, the same time intervals of hepatocyte proliferation while, HSCs were activated only three days postoperatively. This could point to an integrative role between hepatocytes and nonparenchymal cells. Kupffer cells could play a role in stimulating hepatocyte replication three days postoperatively and terminating it at day seven as noted by PCNA assessment. Kupffer cells are predominant source of both stimulatory (TNF and IL-6) and inhibitory (TGF- $\beta$ ) mediators that are secreted early during hepatocytes replication. However, the regenerating hepatocytes are transiently resistant to TGF- $\beta$ 's inhibitory action that may result from down-regulation of the receptors or upregulation of signalling inhibitors ${ }^{[68]}$. Hepatic stellate cells could be involved in the establishment of the sinusoids and their walls that will supply the proliferating hepatocytes. This could be supported by some authors who mentioned that HSCs could secrete extracellular matrix 3-4 days after PH to reestablish the connection between hepatocytes and the sinusoidal epithelium ${ }^{[69]}$.

\section{CONFLICT OF INTEREST}

There are no conflict of interest.

\section{REFERENCES}

1. Joshi RM, Palep JH, Sayed S and Mehta S. (2005): Hepatic resection: An insight. Indian J Surg; 67:13-20.

2. Parkin DM, Bray F, Ferlay J and Pisani P. (2001): Estimating the world cancer burden: Globocan 2000. Int J Cancer; 94: 153-156.

3. Mazzaferro V, Llovet JM, Miceli R, Bhoori S, Schiavo M, Mariani L, et al., (2009): Predicting survival after liver transplantation in patients with hepatocellular carcinoma beyond the Milan criteria: a retrospective, exploratory analysis. Lancet Oncol; 10(1): 35-43.

4. Redaelli CA, Wagner M, Krähenbühl L, Gloor B, Schilling MK, Dufour JF and Büchler MW. (2002): Liver surgery in the era of tissue-preserving resections: Early and late outcomein patients with primary and secondary hepatic tumors. World J Surg; 26(9): 1126-1132.

5. Malagó M, Testa G, Frilling A, Nadalin S, ValentinGamazo C, Paul A, Lang H, Treichel U, Cicinnati V,Gerken G, Broelsch CE and Höckerstedt AV. (2003): Right living donor liver transplantation: An option for adult patients - single institution experience with 74 patients. Ann Surg; 238(6): 853-863.

6. Schlag PM, Benhidjeb T and Stroszczynski C. (2002): Resection and local therapy for liver metastases. Best Pract Res Clin Gastroenterol; 16: 299-317.

7. Viebahn CS and Yeoh GC. (2008): What fires prometheus? The link between inflammation and regeneration following chronic liver injury. Int J Biochem Cell Biol; 40(5): 855-73. 
8. Gebhardt R, Baldysiak-Figiel A, Krügel V, Ueberham E and Gaunitz F. (2007): Hepatocellular expression of glutamine synthetase: an indicator of morphogen actions as master regulators of zonation in adult liver. Prog Histochem Cytochem; 41: 201-266.

9. Michalopoulos GK. (2010): Liver regeneration after partial hepatictomy-Critical analysis of mechanistic dilemmas. The american Journal of pathology; 176(1): 2-13.

10. Vassiliou I, Lolis E, Nastos C, Tympa A, Theodosopoulos T, Dafnios N, Fragulidis G, Frangou M, Kondi-Pafiti A and Smyrniotis V. (2010): the combined effect of erythropoietin and granulocyte macrophage colony stimulating factor on liver regeneration after major hepatectomy in rats. World Journal of Surgical Oncology; 8: 57.

11. Balabaud C, Bioulac-Sage $\mathrm{P}$ and Desmoulière A. (2004): The role of hepatic stellate cells in liver regeneration. J Hepatol; 40: 1023-1026.

12. Shergill U, Das A, Langer D, Adluri RS, Maulik $\mathrm{N}$ and Shah VH. (2010): Inhibition of VEGF and NO dependent angiogenesis does not impair liver regeneration. AJP-Regul Integr Comp Physiol; 298: R1279-R1287.

13. Friedmann SL. (2008): Hepatic stellate cells: protean, multifunctional, and enigmatic cells of the liver. Physiol Rev; 88: 125-172.

14. Higgins GM and Anderson RM. (1931): Experimental pathology of the liver. I: restoration of the liver of the white rat following partial surgical removal. Arch Pathol; 12: 186- 202.

15. Greif F, Ben-Ari Z, Taya R, Pappo O, Kurtzwald E Cheporko Y, Ravid A and Hochhauser E. (2010): Dual Effect of Erythropoietin on Liver Protection and Regeneration after Subtotal Hepatectomy in Rats. Liver transplantation; 16: 631-638.

16. Cynthia, M.; Kahn, B.A.; Dana, G.A.; Dave, P.A. and leo, B.J. (2006): "The Merk Veterinary Manual" 9th edition. Educational partnership with merial Ltd. Merk and Co., Inc.

17. Bockhorn M, Goralski M, Prokofiev D, Dammann P, Grünewald P, Trippler M, Biglarnia A, Kamler M, Niehues EM, Frilling A, Broelsch CE and Schlaak JF. (2007): VEGF is important for early liver regeneration after partial hepatectomy. J Surg Res; 138(2): 291-9.

18. Bancroft JD and Gamble M.(2008): Theory and Practice of histological techniques. 7th edition, John Bancroft, Churchill Livingstone, Edinbrugh, London, Madrid, New York and Tokyo; 147-150.

19. Miller K. (2002): Immunocytochemical techniques. In: Bancorft JD, Gample M. Theory and practice of histological techniques, Ch: 20. 5th ed. Toronto, London, New York: Churchill Livingstone 2002; P. 421.
20. Chen J-A, Shi M, Li J-Q and Qian C-N. (2010): Angiogenesis: multiple masks in hepatocellular carcinoma and liver regeneration. Hepatol Int; 4: 537547.

21. Michalopoulos GK. (2007): Liver Regeneration. J. Cell. Physiol; 213: 286-300.

22. Palmes D and Spiegel HU. (2004): Animal models of liver regeneration. Biomaterials; 25: 1601-1611.

23. Mitchell C, Nivison M, Jackson LF, Fox R, Lee DC, Campbell JS and Fausto N. (2005): Heparin-binding epidermal growth factor-like growth factor links hepatocyte priming with cell cycle progression during liver regeneration. J Biol Chem; 280: 2562-2568.

24. Cao H, Jiong Yu J, Xu W, Jia X, Yang J, Pan Q, Zhang Q, Sheng G, Li J, Pan X, Wang Y and Li L. (2009): Proteomic analysis of regenerating mouse liver following $50 \%$ partial hepatectomy. Proteome Science; 7: 48 .

25. Abdalla OA, Awad MA, Helmy SA and Abdou MT. (2009): Histological and Clinicopathological Studies Following Partial Hepatectomy in Dogs. J Vet Anat; 2(1): $17-34$.

26. Aguiar LRF, Nassif PAN, Ribas CAPM, Czeczko NG, Ribas MM, Júnior CHM and Wendle E. (2011): Liver regeneration after partial hepatectomy in rats submitted to post-hepatic portal hypertension. ABCD Arq Bras Cir Dig; 24(2): 144-151.

27. Kumar V, Abbas AK, Fausto N and Aster J. (2010): Robbins and Cotran Pathologic Basis of Disease. 8th edn. Elsevier.

28. Greene AK, Wiener S, Puder M, Yoshida A, Shi B, Perez-Atayde AR, Efstathiou JA, Holmgren L, Adamis AP, Rupnick M, Folkman J and O'Reilly MS. (2003): Endothelial-directed hepatic regeneration after partial hepatectomy. Ann Surg; 237: 530-535.

29. Zou Y, Bao Q, Kumar S, Hu M, Wang G-Y and Dai G. (2012): Four Waves of Hepatocyte Proliferation Linked with Three Waves of Hepatic Fat Accumulation during Partial Hepatectomy-Induced Liver Regeneration. PLos One; 7(2): e30675.

30. Ibirogba SB, Spearman CW, Mall A, Shepherd E, Lotz Z, Tyler M and Kahn D. (2005): Restoration of liver mass after partial hepatectomy--implications for living donor liver transplantation. S Afr J surg; 43(3): 70-2.

31. Minagawa M, Oya H, Yamamoto S, Shimizu T, Bannai M, Kawamura H, Hatakeyama K and Abo T. (2000): Intensive expansion of natural killer T cells in the early phase of hepatocyte regeneration after partial hepatectomy in mice and its association with sympathetic nerve activation. Hepatology; 31(4): 907-15. 
32. Zhang J-J, Niu J-X, Dong C-X and Meng X-K. (2011): Portal vein arterialization used in partial hepatectomy maintains liver regeneration. Sci. Res. Essays; 6(30): 6325-6330.

33. Miyaoka Y, Ebato K, Kato H, Arakawa S, Shimizu S and Miyajima A. (2012): Hypertrophy and unconventional cell division of hepatocytes underlie liver regeneration. Curr boil; 22: 1166-1175.

34. Miyaoka Y and Miyajima. (2013): To divide or not to divide: revisiting liver regeneration. Cell devision; 8: 8 .

35. Popescu R, Filimon MN, Dumitrescu G, Ciochina LP, Dumitrascu V, Vlad D and Verdes D. (2012): Histological and Morphometrical Studies in Liver Regeneration in Mice. Animal Sciences and Biotechnologies; 45(2): 203-207.

36. Rudnick DA and Davidson NO. (2012): Functional Relationships between Lipid Metabolism and Liver Regeneration. Int J Hepatol; ID: 549241.

37. Morales-González JA, Jiménez-García LF, GuitérrezSalinas J, Sepúlveda J, Leija-Salas A and HernándezMuñoz R. (2001): Effects of ethanol administration on hepatocellular ultrastructure of regenerating liver induced by partial hepatectomy. Dig Dis Sci; 46(2): 360-9.

38. Budny T, Palmes D, Stratmann U, Minin E, Herbst $\mathrm{H}$ and Spiegel HU. (2007): Morphologic features in the regenerating liver-a comparative intravital, lightmicroscopical and ultrastructural analysis with focus on hepatic stellate cells. Virchows Arch; 451(4): 781-91.

39. Tang W, Liang K, Wang J, Du L and Zhary W. (2000): The effects of PHGF on hepatocytes DNA synthesis after partial hepatectomy in rats. J Tongji Med Univ; 18(1): 25-7.

40. Okeda M, Sakairi T, Kusakabe M, Goto K, Tsuchiya T, Sugimoto J, Sano F, Mutai M and Morohashi T. (2002): immunohistochemical localization of transoforming growth factor alpha in regenerating rat liver. J Vet. Med sci; 64(11): 1045-8.

41. Mabuchi A, Mullaney I, Sheard PA, Zimmermann A, Senoo H and Wheatley AM. (2004): Role of hepatic stellate cells in the early phase of liver regeneration in rat: formation of tight adhesion to parenchymal cells. Comp Hepatol; 3(1): S29-37.

42. Sanz-Cameno P, Trapero-Marug M, Chaparro M, Jones EV and Moreno-Otero R. (2010): Angiogenesis: From chronic Liver inflammation to hepatocellular carcinoma. Journal of Oncology; 7 pages.

43. Wack KE, Ross MA, Zegarra V, Sycko LR, Watkins SC and Stolz DB. (2001): Sinusoidal ultrastructure evaluated during the revascularization of regenerating rat liver. Hepatology; 33: 363-378.
44. Meijer C, Wiezer MJ, Diehl AM, Schouten HJ, Schouten HJ, Meijer S, van Rooijen N, van Lambalgen AA, Dijkstra CD and van Leeuwen PA. (2000): Kupffer cell depletion by CI2MDP-liposomes alters hepatic cytokine expression and delays liver regeneration after partial hepatectomy. Liver; 20(1): 66-77.

45. Abshagen K, Eipel C, Kalff JC, Menger MD and Vollmar B. (2007): Loss of NF-kB activation in Kupffer cell-depleted mice impairs liver regeneration after partial hepatectomy. Am J Physiol Gastrointest Liver Physiol; 292(6): G1570-7.

46. Amemiya H, Kono H and Fujii H. (2011): Liver regeneration is impaired in macrophage colony stimulating factor deficient mice after partial hepatectomy: the role of M-CSF induced macrophages. J Surg Res; 165(1): 59-67.

47. Xu C-S, Jiang Y, Zhang L-X, Chang C-F, Wang G-P, Shi R-J and Yang Y-J. (2012): The Role of Kupffer Cells in Rat Liver Regeneration Revealed by CellSpecific Microarray Analysis. Journal of Cellular Biochemistry; 113: 229-237.

48. Xiang S, Dong H-H, Liang H-F, He S-Q, Zhang W, Li C-H, Zhang B-X, Zhang B-H, Jing K, Tomlinson S, Rooijen NV, Jiang L, Cianflone K and Chen X-P. (2012): Oval Cell Response Is Attenuated by Depletion of Liver Resident Macrophages in the 2-AAF/Partial Hepatectomy Rat. PLos One; 7(4): e35180.

49. Ping C, Xiaoling D, Jin Z, Jiahong D, Jiming D and Lin Z. (2006): Hepatic sinusoidal endothelial cells promote hepatocyte proliferation early after partial hepatectomy in rats. Archives of Medical Research; 37: $576-583$.

50. Fernandez M, Semela D, Bruix J, Colle I, Pinzani M and Bosch J. (2009): Angiogenesis in liver disease. J Hepatol; 50(3): 604-620.

51. Lowes KN, Croager EJ, Olynyk JK, Abraham LJ and Yeoh GCT. (2003): Oval cell-mediated liver regeneration: Role of cytokines and growth factors. Journal of Gastroenterology and Hepatology; 18 : 4-12.

52. Furchtgott LA, Chow CC and Periwal V. (2009): A Model of Liver Regeneration. Biophysical Journal; 96: 3926-3935.

53. Klemm K, Eipel C, Cantre D, Abshagen K, Menger MD and Vollmar B. (2008): Multiple Doses of Erythropoietin Impair Liver Regeneration by Increasing TNF-a, the Bax to Bcl-xL Ratio and Apoptotic Cell Death. PLos One; 3(12): e3924.

54. Sell S. (2001): Heterogeneity and plasticity of hepatocyte lineage cells. Hepatology; 33: 738-750. 
55. Diehl AM. (2002): liver regeneration. Frontiers in Bioscience; 7: e301-314.

56. Ferri D, Moro L, Mastrodonato M, Capuano F, Marra E, Liquori GE and Greco M. (2005): Ultrastructural zonal heterogeneity of hepatocytes and mitochondria within the hepatic acinus during liver regeneration after partial hepatectomy. Biol. Cell; 97: 277-288.

57. Gaudio E, Franchitto A, Pannarale L, Carpino G, Alpini G, Francis H, Glaser S, Alvaro D and Onori P. (2006): Cholangiocytes and blood supply. World J Gastroenterol; 12(22): 3546-3552.

58. Taira Z, Shiraishi M and Ueda Y. (2005): An Abnormal Proliferation at Day Four on 70\% Partial Hepatectomy of Rats. J.Hard Tissue Biology; 14(4): 351-352.

59. Furnusa CC, Indab AM, Andrinia LB, Garcíab MN, Garcíaa AL, Badrána AF and Errecaldea AL. (2003): Chronobiology of the proliferative events related to angiogenesis in mice liver regeneration after partial hepatectomy. Cell Biology International; 27(4): $383-$ 386.

60. Buren II GV, Yang AD, Dallas NA, Gray MJ, Lim SJ, Xia L, Fan F, Somcio R, Wu Y, Hicklin DJ and Ellis LM. (2008): Effect of Molecular Therapeutics on Liver Regeneration in a Murine Model. J Clin Oncol; 26: 1836-1842.

61. Sato M, Suzuki S and Senoo H. (2003): Hepatic stellate cells: unique characteristics in cell biology and phenotype. Cell Struct Funct; 28: 105-112.

62. Mabuchi A, Mullaney I, Sheard PW, Hessian PA, Mallard BL, Tawadrous MN, Zimmermann A, Senoo $\mathrm{H}$ and Wheatley AM. (2004): Role of hepatic stellate cell/hepatocyte interaction and activation of hepatic stellate cells in the early phase of liver regeneration in the rat. J Hepatol; 40(6): 910-916.
63. Bohm F, Kohlerly UA, Speicherly T and Werner S (2010): Regulation of liver regeneration by growth factors and cytokines. EMBO Mol Med; 2: 294-305.

64. Kalinichenko VV, Bhattacharyya D, Zhou Y, Gusarova GA, Kim W, Shin B and Costa RH. (2003): Foxf1 $\mathrm{p} / 2$ mice exhibit defective stellate cell activation and abnormal liver regeneration following $\mathrm{CCl} 4$ injury. Hepatology; 37: 107-117.

65. Issa $\mathrm{R}$, Zhou $\mathrm{X}$, Trim N, Millward-Sadler H, Krane S, Benyon C and Iredale J. (2003): Mutation in collagen-1 that confers resistance to the action of collagenase results in failure of recovery from CCl4induced liver fibrosis, persistence of activated hepatic stellate cells, and diminished hepatocyte regeneration. FASEB J; 17: 47-49.

66. Uyama N, Shimahara Y, Kawada N, Seki S, Okuyama H, Iimuro Y and Yamaoka Y. (2002): Regulation of cultured rat hepatocyte proliferation by stellate cells. Journal of Hepatology; 36: 590-599.

67. Shen K, Chang W, Gao X, Wang H, Niu W, Song L, and Qin X. (2011): Depletion of hepatic stellate cell correlates with severe liver damage and abnormal liver regeneration in acetaminophen- induced liver injury. Acta Biochim Biophys Sin; 43: 307-315.

68. Macias-Silva M, Li W, Leu JI, Crissey MA and Taub R. (2002): Up-regulated transcriptional repressors SnoN and Ski bind Smad proteins to antagonize transforming growth factor-beta signals during liver regeneration. J Biol Chem; 277: 28483-28490.

69. Taub R. (2004): Liver regeneration: from myth to mechanism. Nat Rev Mol Cell Biol; 5(10): 836-47. 


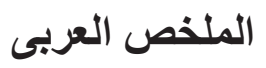

\section{دور الخلايا النجمية الكبدية وتكوين الأعية الاموية في تجدد أنسجة الكبد بعد الاستئصال الجزئح للكبد في ذكور الجرذان البالغه البيضاء: دراسة هستولوجية و هستوكيميائية مناعية الائية}

سعاد جيمى تادروس'، داليا محمد المراكبي، مها محمد ابو جازيهّ، أحمد عبد الرحمن مرسيّ" قسم الهستولوجياـ كليه الطب -جامعه القاهره' - جامعه كفر الشيخ' - جامعه الفيوم

المقدمـة: تناول هذا البحث دراسة استجابة الكبد للتجدد بعد الاستئصال الجر احى الجزئى لحو الي • V\% من أنسجته في الجرذان البيضاء البالغة، كما تناول البحث متابعة عملية التجدد، من خلال وجود مر احل مختلفة من انقسام الخلايا وظهور مستضد الخلية النووي التكاثرى، وربطها بدور الخلايا النجمية الكبدية وكذللك التكوين الجديد للأوعية الدموية. مواد وطرق البحث: استخدم في هذه الدر اسة عدد · ع جرذا من ذكور الجرذان البيضاء البالغة، وقد قسمت هذه الجرذان

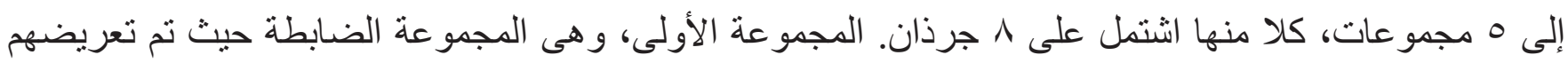

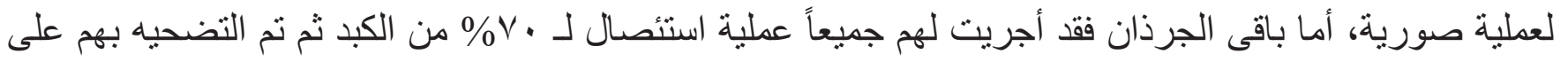

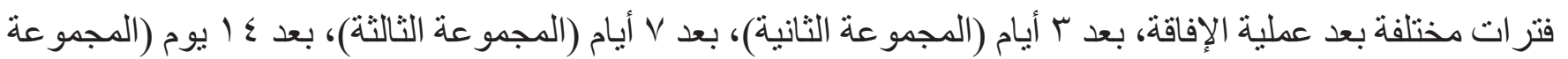

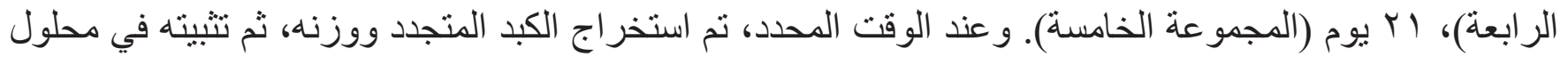
الفورمالين، وجهزت منها قطاعات شمعية (سمك 0 ميكرون) ونم صبغها بالهيماتوكسيلين و الإيوسين، و الصباغات الهيستوكيميائية المناعية للكثف عن وجود مستضد الخلية النووي التكاثرى، عامل النمو البطانى الوعائى و ألفا أكتين العضلات الملساء. وقد تم عمل دراسات لقياس متوسط نسبة وزن الكبد إلى وزن الجسم كله والتي أظهرت زيادة

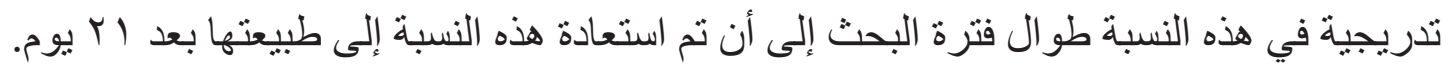

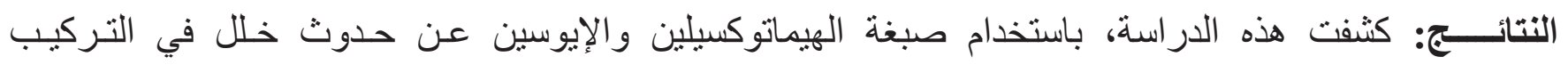

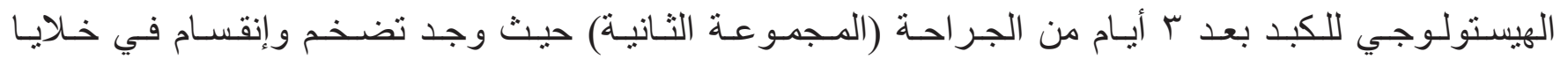

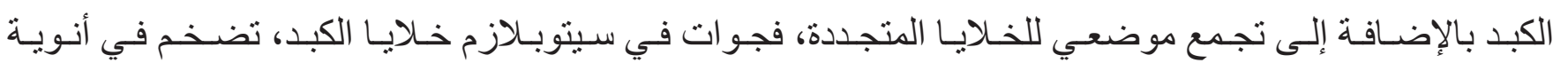

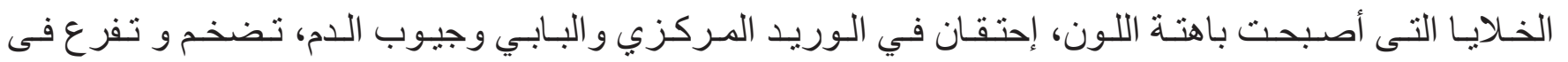

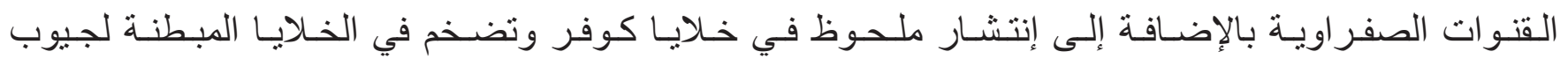

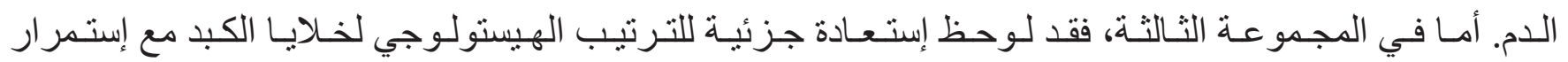

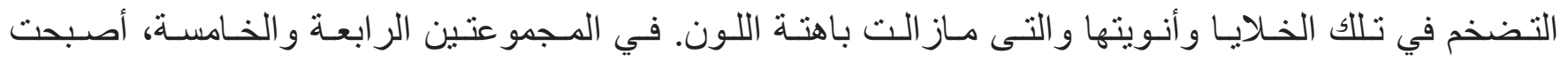

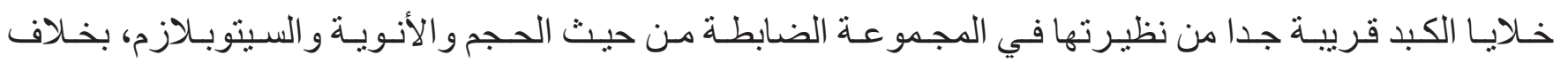

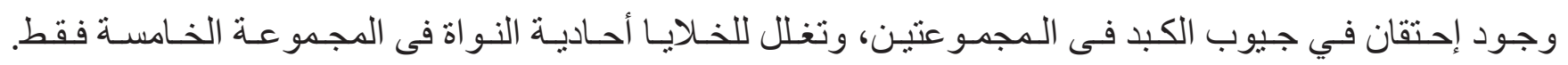

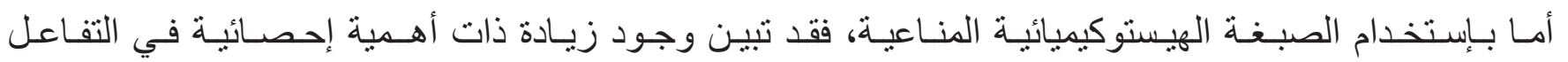




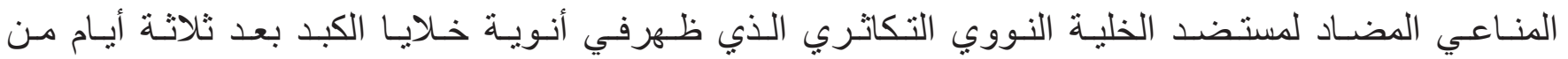

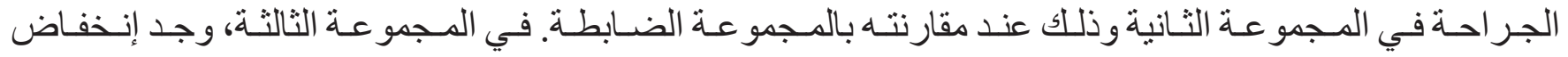

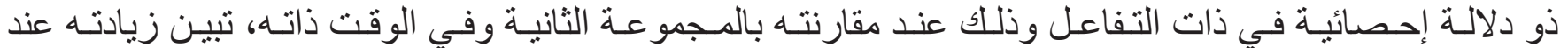

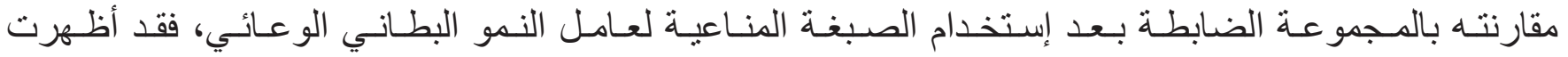

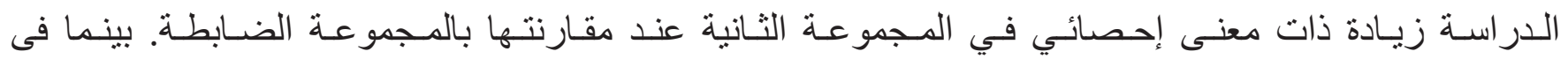

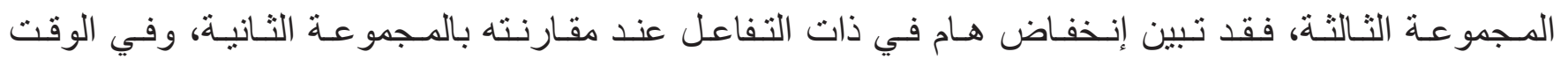

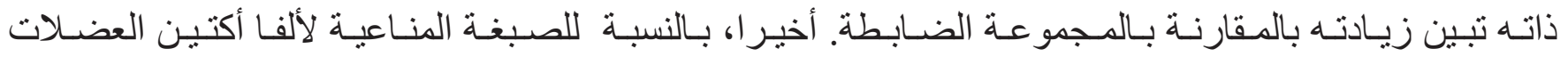

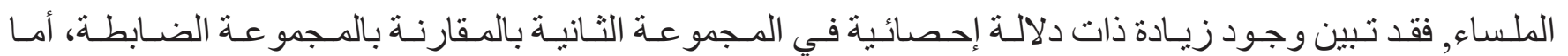

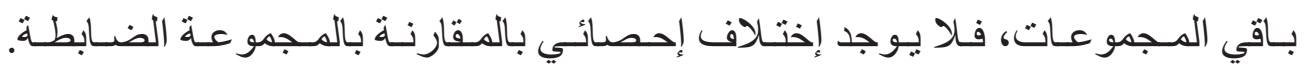
الأستنتاج:

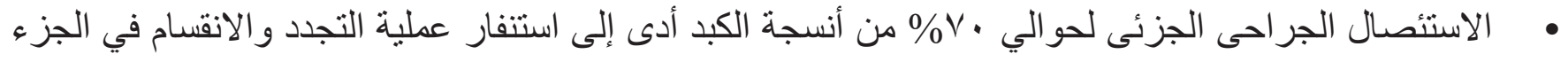

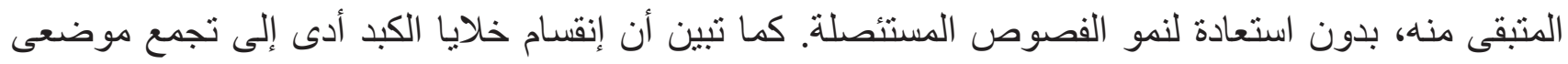
للخلايا المتجددة في مر احل مبكرة بعد العملية، مع حدوث خلل في ترتيب خلايا الكبد والذى تم استعادته في الأيام التالية للجر احة. • تبين نشاط و اضح في الخلايا النجمية الكبدية والتي من الممكن أن بكون لها دور هام في تجدد الكبد حيث أنها قد تشارك في تكوين جدار جيوب الدم الجديدة. تبين أن تكأثز خلايا الكبد وتز امن مع ظهور جائ عامل النمو البطانى الوعائى ونشاط الخلايا النجمية الكبدية، يؤكد أن تجدد الكبد عملية دقيقة تحتاج إلى تعاون مشترك بين بين خلايا الكبد المختلفة. • في مجال زر اعة الكبد، تبين من البحث إحتمالية عدم وجود مخاطر صحية على الأجزاء المتبقية من الكبد بالنسبة للمتطو عيين بالتبرع ، من تجدد كامل للأجز اء المستئصلة. التوصيـات: • هناك حاجة ملحة لبذل قصسارى الجهد لإبتكار أدوية جديدة وطرق جر احة تؤدى بدور ها إلى تحفيز الكبد على التجدد،

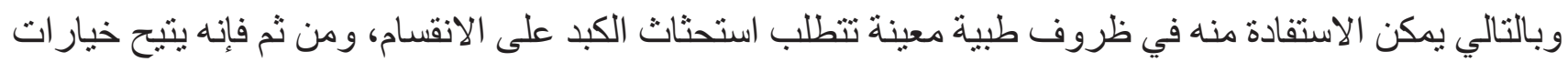
علاج جديدة لمرضى الكبد. • هناك حاجة لإجر اء أبحاث متقدمة ودر اسات معملية للتعمق في معرفة دور الخلايا النجمية الكبدية في تجدد الكبد. 